EdTech ${ }^{\text {Hub }}$

Clear evidence, better decisions, more learning.

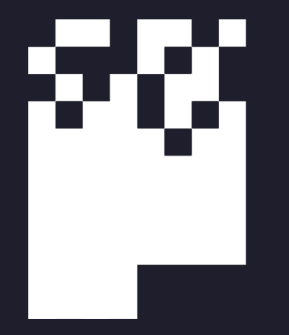

Busara

WORKING PAPER

Understanding Barriers to Girls'

Access and Use of EdTech in Kenya

During Covid-19

Date October 2021

Authors Lara Tembey, Busara Center for Behavioral Economics Jasmin Baier, Busara Center for Behavioral Economics Concilia Ogolla, Busara Center for Behavioral Economics Prithika Mohan, Busara Center for Behavioral Economics

DOI $\quad 10.53832 /$ edtechhub.0048

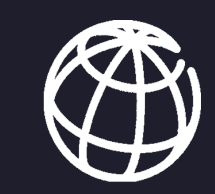

THE WORLD BANK

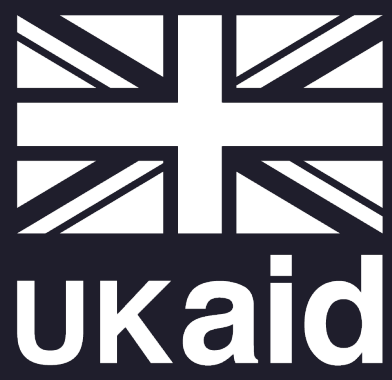

from the British people 


\section{About this document}

\section{Recommended citation}

\section{Licence}

Notes

Acknowledgements
Tembey, L., Baier, J., Ogolla, C., Mohan, P. (2021). Understanding Barriers to Girls' Access and Use of EdTech in Kenya During Covid-19. Working Paper 37. https://doi.org/10.53832/edtechhub.0048. Available at https://docs.edtechhub.org/lib/JZM7W6QE. Available under Creative Commons Attribution 4.0 International, https://creativecommons.org/licenses/by/4.0/.

Creative Commons Attribution 4.0 International https://creativecommons.org/licenses/by/4.0/ You - dear readers - are free to share (copy and redistribute the material in any medium or format) and adapt (remix, transform, and build upon the material) for any purpose, even commercially. You must give appropriate credit, provide a link to the license, and indicate if changes were made. You may do so in any reasonable manner, but not in any way that suggests the licensor endorses you or your use.

EdTech Hub is supported by UK aid and the World Bank; however, the views expressed in this document do not necessarily reflect the views of the UK Government or the World Bank.

Christina Myers and Tom Kaye (EdTech Hub) for supervising this research and providing input to its design, methodology, delivery, and results. From Ubongo, we would like to thank Nisha Ligon, Fatema Ismailjee, Clíodhna Ryan, and all of their colleagues who supported us with understanding the landscape, instrument and research tool design, as well as product ideation and creation.

Loise Gichuhi, Akanksha Bapna, Tom Kaye, and Christina Myers 


\section{Abstract}

The Covid-19 pandemic resulted in the closure of approximately 90,000 schools across Kenya, causing over 18 million pre-primary, primary, and secondary school learners to be out of school throughout 2020. These lockdown measures of Covid-19 are expected to amplify gender inequalities in education and girls' access to school, with girls likely to have experienced losses in learning during the pandemic to a greater extent than their male counterparts ( Malala Fund, 2020). To enable continued learning during this period, numerous education technology (EdTech) solutions and products have been developed to enable remote learning. This technology can be a powerful tool for girls. Studies have shown that girls engage more than boys when provided with the same level of access to technology, and receive more benefits beyond the realm of formal education such as an increase in access to economic opportunities and a greater ability to make informed decisions about their own health (^Webb et al., 2020).

However, social inequalities, norms and technological constraints can disproportionately prevent girls from accessing and benefiting from EdTech (^Crompton et al., 2021). As such, EdTech interventions and products need to be designed and implemented prioritising gender considerations, otherwise, they risk increasing the digital gender divide both in terms of access and use of digital technologies and the internet and the development of skills needed to use digital technologies ( $\uparrow$ Kuroda et al., 2019).

Our qualitative and quantitative research looked at how access and usage of learning content and edutainment through smartphone and low-tech (such as radio, Interactive Voice Response, TV) EdTech solutions can be optimised to ensure inclusivity of girls, in particular, focusing on the caregiver as the gatekeeper for access to EdTech resources. In terms of access, our research found that caregivers are primarily concerned about financial resources, books and tutors, and often do not consider using EdTech to access educational resources when they are looking for support for their children. Further, our research showed that digital literacy, caregiver involvement, norms about technology for education, and intention are the most promising levers to improve access and use of educational material. 


\section{Contents}

$\begin{array}{ll}\text { Abstract } & 3\end{array}$

$\begin{array}{ll}\text { Abbreviations and acronyms } & 6\end{array}$

$\begin{array}{ll}\text { Executive summary } & \mathbf{7}\end{array}$

$\begin{array}{ll}\text { 1. Introduction } & 12\end{array}$

$\begin{array}{ll}1.1 \text { Background to the study } & 12\end{array}$

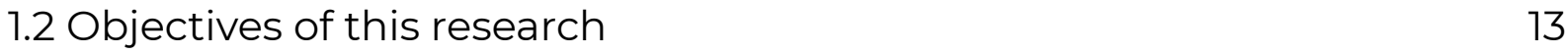

$\begin{array}{ll}1.3 \text { Research questions } & 14\end{array}$

1.4 What this paper adds to the knowledge base $\quad 15$

$\begin{array}{ll}1.5 \text { Structure } & 16\end{array}$

$\begin{array}{ll}\text { 2. Literature review } & 17\end{array}$

3. Methodology 21

3.1 Research design and methodology 21

3.2 Research instruments/tools 30

3.3 Stakeholders 33

3.4 Ethical considerations 33

3.5 Challenges and limitations 33

4. Results $\quad 35$

4.1 Sample description 35

4.2 Barrier and levers improving access to and use of EdTech 38

4.3 Communicating EdTech compatibility with school curricula

4.4 Theoretical access to distribution channels 50

4.5 Awareness of products beyond TV offerings 53

4.6 Further insights into secondary research questions and from
prototyping testing

5. Policy implications $\quad 58$

6. Conclusions $\quad 62$

$\begin{array}{ll}\text { Bibliography } & 64\end{array}$ 
EdTech Hub

Annex 1 - Construction of outcome variables and indices

69

Annex 2 - Fictional story

72 


\section{Abbreviations and acronyms}

Busara

COMESA

Cso

FGD

GBV

HMW

IVR

KES

KCPE

KICD

MoE

NGO

USSD
Busara Center for Behavioral Economics

Common Market for Eastern and Southern Africa

Civil society organisation

Focus group discussion

Gender-based violence

'How might we...?' statements

Interactive Voice Response

Kenyan Shillings

Kenya Certificate of Primary Education

Kenya Institute of Curriculum Development

Ministry of Education

Non-governmental organisation

Unstructured Supplementary Service Data 


\section{Executive summary}

In light of the ongoing Covid-19 pandemic and the disruption that this has caused to education globally, there is a significant demand for increased remote learning resources and content and evidence that fosters continuous education in policy and programming. Opportunities that leverage EdTech to target girls, who are likely to be disproportionately affected by the pandemic, have been of particular interest for many governments ( Malala Fund, 2020).

This is the case for Kenya, where the Kenya Ministry of Education Covid-19 Response Plan highlights the importance of leveraging EdTech to target girls. Specifically, the Response Plan outlines Kenya's strategy to provide access to quality, equitable, and inclusive education to learners, during and after the crisis, to ensure continued learning, facilitate the production of online teaching and learning materials, and develop and implement intervention programmes targeting the marginalised and most vulnerable learners, especially girls (^State Department of Early Learning and Basic Education, 2020).

In response to the challenges Covid-19 posed to the Kenyan education system, including the shutdown of schools, EdTech Hub partnered with The Busara Center for Behavioral Economics, and Ubongo, an edutainment provider in East Africa, to carry out a study to understand the barriers to access and use of EdTech in low-income settings in Kenya, for girls aged 7-14 years.

\section{Purpose}

The purpose of this study was guided by the following objectives:

- To increase understanding of caregivers' decision-making processes in enabling or undermining girls' access to EdTech.

- To identify scalable interventions that can increase access to and use of EdTech among girls.

The primary research questions we aimed to answer through our study were:

- Which barriers exist and are particularly hindering for girls to access EdTech, both structurally (access to infrastructure / devices) and in terms of social norms / attitudes / beliefs? How can these be addressed?

- What in Ubongo's edutainment offers, in terms of content, access, or usage could be improved to better address the needs of girls and women during Covid-19? 


\section{Methods}

This study was conducted in two phases. The first phase was a primary research phase, employing a mixed-methods approach and targeting caregivers of 7-14-year-olds. Busara carried out 58 qualitative interviews that focused on the households' daily experiences and attempted to learn about the at-home learning journeys of caregivers and children. Empathy and journey maps ${ }^{\top}$ were used for qualitative data analysis. A quantitative survey of 494 caregivers focused on understanding structural and non-structural predictors of EdTech access and the caregivers' decision-making processes. Regression analysis and descriptive statistics supported insight generation of our quantitative data.

Results from Phase 1 informed Phase 2 - a human-centred design thinking process with Ubongo. This involved a series of co-design workshops, which resulted in the development and rapid testing of prototypes.

\section{Key findings}

The following research findings have a particular focus on girls and their access to and use of educational technology.

1. The research identified four key factors that have the potential to be leveraged to improve access and use of EdTech for girls to support learning at home. These are:

- Improving caregiver digital literacy i.e., how comfortable a caregiver is using a smartphone or tablet unassisted.

- Increasing caregiver involvement in their child's education in terms of time spent but also encouragement given, and a conducive environment set up for learning at home.

- Changing norms about technology for education by increasing the acceptance of $\mathrm{TV}$, radio, feature phones and smartphones as useful and appropriate modalities for learning

- Supporting intentions to provide equal educational opportunities for all children

2. Caregivers report attempting to provide learning resources for their children in equal measure regardless of their gender. They, however, raise children differently based on gender. Male children tend to spend

\footnotetext{
'An 'empathy map' is a collaborative visualisation used to articulate what we know about a particular type of user. A 'journey map' is a visualisation of the process that a person goes through in order to accomplish a goal.
} 
more time with the father, while female children spend more time with the mother doing household chores.

3. When it comes to gender norms, intention and reality display a large gap. In every single one of our interviews, people agreed that education for both genders should be prioritised and self-reported that there was no difference in their households. However, when asked about behaviours within their communities, all participants stated that generally, within their communities, the behaviour is to prioritise the education of males over females.

More general findings, that are applicable to caregivers with both / either boys and girls include:

1. Compatibility with the curriculum, price, quality, and government license / approval are the most important factors caregivers consider when making decisions about educational resources for their children.

2. Most caregivers focus primarily on needing financial resources for textbooks. This concern is most likely rooted in a lack of awareness of how other materials link to skills needed for national examinations.

3. Most households primarily access EdTech resources through television sets. While most caregivers believe in the opportunities other forms of EdTech might provide, their concerns around safety, inappropriate behaviour, and potential dependence on technology mostly hinder regular use of, for example, smartphones.

4. The female caregiver makes most decisions around children's education in a household as they are deemed to know more about their children's needs.

5. Two of the greatest gaps identified in accessing and using EdTech were a lack of guidance and a lack of conducive learning environments. Professional advice by trusted community members and teachers significantly reassured caregivers and provided them with a sense of control over the situation, but this was typically perceived as not available or not enough.

\section{Policy implications}

The following insights have important implications for Kenyan Government policy.

- A lack of awareness of often free, accessible EdTech resources is a barrier to EdTech uptake and learning at home. Increasing awareness through 
communications campaign support could be an effective way of highlighting the benefits of EdTech and promoting it as 'proper' learning material.

- The link between the national curriculum and available EdTech resources needs to be made more salient. The government has a potentially large role to play in this through official endorsements or approvals for EdTech content that is based on the curriculum and can be used as a supplementary learning resource. The government could engage EdTech producers directly or provide guidance on how best to make the link between the curriculum and their content clearer.

- More guidance is needed from trusted professionals, particularly teachers, in terms of which resources are relevant and useful for children at a given age / stage in their educational journey, as well as support to answer questions arising from EdTech content. For the former, the government could provide support by creating a list of available EdTech resources and the topics that they cover for teachers so that they can share this with caregivers and learners directly. Further, teachers need to be provided with additional support (training and resource packages) to be able to answer questions related to EdTech resources if required.

- Interventions that aim to increase caregiver digital literacy, caregiver involvement in their child's education, and to improve norms about the use of technology as a tool for education should focus on targeting female caregivers, given their role as the primary decision-maker in a household about education.

- As opportunities, behaviour, and engagement with EdTech may differ between boys and girls, campaigns / interventions need to be designed with these considerations and differences in mind.

Due to the correlational model used within our study, we recommend further research to establish causal links. Further, it will also be important to understand the impact that EdTech can have on norms and learning outcomes, with a focus on girls, in order to evaluate if investment in EdTech is an efficient, equitable, and cost-effective way to facilitate learning. 


\section{Introduction}

This section presents the background and the purpose of the study, contribution to literature, and research questions. It also summarises the implications for policy and practice.

\subsection{Background to the study}

Primary and secondary school-age girls around the world face disproportionate challenges in accessing and staying in education as a result of structural inequalities. Globally, access to education and high dropout rates for girls were further aggravated by the Covid-19 pandemic and the progress made to address these challenges was ultimately slowed down (^Giannini \& Albrectsen, 2020). According to UNESCO, more than 1.5 billion learners in approximately 195 countries around the world were affected by the closure of schools and universities due to the Covid-19 pandemic (^UNESCO, 2020). A study by the Malala Fund estimates that approximately 20 million more secondary school-age girls could be out of school after the crisis has passed (^Malala Fund, 2020).

Kenyan girls are no exception. A study conducted by Human Rights Watch revealed that the education of 18 million learners had come to a temporary halt as 90,000 schools across Kenya were closed to curb the potential and fatal spread of the virus ( $\uparrow$ Cordeiro, 2020). The closure of these schools and resulting limitation of safe learning spaces contributed to violence against girls and teenage pregnancies. A study conducted by the Population Council to assess the impact of Covid-19 in Kenya found 39\% of girls reported physical violence, $4 \%$ of 15-19-year-old adolescent girls were pregnant or had recently had a baby, and $16 \%$ of girls did not return to school when schools reopened in January 2021 (^Presidential Policy and Strategy Unit (Kenya) \& Population Council, 2021). This, as well as anticipated learning losses from school closures, particularly for girls, means it is imperative to continue to engage girls in learning and education to discourage them from dropping out of school.

In a bid to counter learning losses due to school closures during the Covid-19 pandemic, EdTech was considered the most appropriate alternative for the continuation of learning through remote channels (^GSMA, 2020c; ^World Bank, 2020). However, there are also challenges when it comes to using EdTech as an alternative to traditional learning as access tends to be unequal, especially for poor and rural households, as well as for vulnerable groups. One challenge for such households is access to electricity and the internet - both in terms of access and cost. The electricity access rate in Kenya is currently at 
$75 \%$, as disclosed during a joint meeting of the Common Market for Eastern and Southern Africa (COMESA) Ministers responsible for transport and communication, information technology and energy on 2 June 2021 (^Common Market for Eastern and Southern Africa (COMESA), 2021).

Although these known structural barriers are important, there is reason to believe that both cost of connectivity and hardware will be reduced over time, and as such EdTech is still a promising option to promote and improve learning at home - be it to relieve the side effects of a pandemic or epidemic, to reach disadvantaged and vulnerable groups, or to engage with other out-of-school children.

What has been studied to a much lesser extent is the impact of non-structural levers and barriers once connectivity and affordability are achieved. Uptake of EdTech solutions does not only depend on the theoretical ability to access and use EdTech, but also on the knowledge, attitudes, and behaviour around choosing to embrace and use EdTech resources.

The Busara Center for Behavioral Economics (Busara), in partnership with Ubongo and supported by EdTech Hub, carried out a study to learn about and address the challenges outlined above. Specifically, we addressed the challenge that any digital gender gap could exclude girls from innovations or compound gender disparities in education, especially in the context of the ongoing Covid-19 pandemic and the proliferation of EdTech solutions. In Phase 1 of our study, we aimed to better understand key barriers preventing girls' access to and use of EdTech. Using these insights, in Phase 2, we underwent a human-centred design thinking process with Ubongo to co-design and test prototypes that look to overcome the barriers preventing girls' access and use of EdTech.

\subsection{Objectives of this research}

The aim of this research is to increase the evidence base on barriers to girls' access to and use of EdTech, and present designed, tested, and scalable solutions to address these barriers. Specifically, we focused on non-structural barriers such as gender norms and attitudes, and how these may influence access and uptake. We aimed to understand caregivers' decision-making processes in detail during their journey from noticing a problem to identifying solutions and choosing the most suitable one for themselves and their children. Moreover, we considered how the distribution and usage of resources for learning and edutainment through smartphone and low-tech 
(radio, IVR ${ }^{2}$, USSD 3 , TV) EdTech solutions can be optimised to ensure inclusivity of girls, in particular focusing on the caregiver as the gatekeeper for access.

\subsection{Research questions}

Our study aimed to answer the following research questions:

1. Which barriers exist and are particularly hindering for girls to access EdTech, with a particular focus on non-structural barriers such as social norms / attitudes / beliefs? How can these be addressed?

a. How do caregivers make decisions about encouraging the use of edutainment, smartphones, and low-tech (radio, IVR, USSD, TV) education solutions for their children? What have they found particularly valuable for encouraging girls?

b. Which distribution channels are girls and women most likely to have access to in the face of Covid-19?

2. What in Ubongo's edutainment offers, in terms of content, access or usage, could be improved to better address the needs of girls and women during Covid-19?

As outlined in our results in Section 4, other questions we were able to indicatively explore with the data we collected but which were not prioritised in the research design and instruments, included:

1. How far was the sudden increase in EdTech offerings and material helpful, and for whom was this closer to an overwhelming choice overload? How can these caregivers and learners be supported in navigating the landscape?

2. Does it matter to caregivers whether content / material is curriculum-based and / or licensed or approved by the government during Covid-19?

3. What type of support is needed to facilitate the use of resources for learning and edutainment through smartphone and low-tech (radio, IVR, USSD) EdTech solutions for girls during Covid-19?

We believe these questions could be further explored in future studies.

\footnotetext{
${ }^{2}$ Interactive Voice Response (IVR) is an automated phone system technology that allows incoming callers to access information via a system of pre-recorded messages without having to speak to an agent.

${ }^{3}$ USSD (Unstructured Supplementary Service Data) is a mobile communication technology that is used to send text between a mobile phone and an application program in a mobile network.
} 


\subsection{What this paper adds to the knowledge base}

Numerous EdTech solutions and products have been developed to enable remote learning. These EdTech products can be a powerful tool for girls. Studies have shown that girls engage more than boys when provided with the same level of access to technology, and receive more benefits beyond the realm of formal education, such as an increase in access to economic opportunities and a greater ability to make informed decisions about their own health ( $\uparrow$ Webb et al., 2020). Evidence like this can motivate practitioners and policymakers to increase access, however, it is unclear which channels are most effective for doing this. Issues around structural access, including connectivity, affordability of electricity / internet, and hardware access are studied and measured widely (^Internet Society, 2017; ^The World Bank, 2021; 个Omidyar Network, 2019; ^Naylor \& Gorgen, 2020; ^UNICEF, 2020). However, non-structural barriers are much more likely to affect differences in access, uptake, and use of EdTech between girls and boys within a household.

Structural access alone is not sufficient to lead to improved learning outcomes and to close the gender learning gap. ${ }^{4}$ For example, in classrooms, teachers have been found to demonstrate lower expectations around girls' technology competency and enjoyment (^Zelezny-Green, 2014). Behavioural interventions may increase the effectiveness of EdTech resources (^Rodriguez-Segura, 2020), yet in order to design these interventions a better understanding of attitudes, norms, and the drivers of behaviour are needed.

Phase 1 of this study, therefore, aims to add to evidence on the importance of non-structural or attitudinal and behavioural barriers to access. It tries to understand decision-making processes at a deeper level and studies drivers of access and behaviour including motivation, ability, and opportunity. Structural access, which primarily drives opportunity, ${ }^{5}$ is included in the study in order to holistically understand the situation and compare the absolute and relative importance of each element. Finally, Phase 2 of the project aims to support implementing organisations by showing a clear path from primary research evidence to designing products, to promote the use of evidence in product development, which is sometimes a barrier to increased impact in itself (^Tauson \& Stannard, 2018).

\footnotetext{
${ }^{4}$ The learning gap is defined as the disparity in learning outcomes between genders in an educational environment.

${ }^{5}$ In the 'Motivation-Ability-Opportunity' model, the opportunity pillar primarily describes the environment, which includes structural factors like hardware.
} 


\subsection{Structure}

This paper has six sections.

- Section 1 introduces the study, including its purpose and aims.

- Section 2 presents a review of relevant literature.

- Section 3 presents the methodology, which includes research design, an overview of our research tools, stakeholders involved, ethical considerations, and limitations / challenges of the study.

- Section 4 presents the results of the study.

- Section 5 presents policy recommendations.

- Section 6 presents our conclusions. 


\section{Literature review}

Extensive research shows that compared to boys, girls tend to experience significant disadvantages in their educational journey. On a global level, twice as many girls compared to boys never start school ( $\uparrow$ The Education Commission, 2016). Combined with poverty, the compounded disadvantage is even larger. Taking data from 44 countries, boys in the bottom $50 \%$ in terms of income were $75 \%$ more likely to complete Grade 5 than their female counterparts. In the richer half, the advantage is lower (20\%) yet still substantial (^Filmer, 2005). In sub-Saharan Africa, less than 1 in 20 poor, rural girls are on track to complete secondary school (iThe Education Commission, 2016).

In crisis-prone regions, this effect is even more severe. A study conducted by Plan International to assess the impact of the discontinuation of girls' education in crisis-affected countries, found the following disparities (^Plan International UK, 2019, p. 33):

- The female out-of-school rate is 1.8 percentage points higher than the rate for boys at the primary level and 9.4 at the upper secondary level.

- In their lifetime, girls complete roughly one year less of education than boys.

- Youth literacy is 11.4 percentage points lower among girls than among boys.

As the pandemic resulted in school closures in 185 countries, Plan International and UNESCO warned that rising drop-out rates would disproportionately affect teenage girls, further entrenching gender inequities in education, and increasing the danger of sexual exploitation, early pregnancy, and early and forced marriages. Further, approximately $89 \%$ of learners globally were out of school because of the closures. This represented 1.54 billion children and youth enrolled in school or university, including nearly 743 million girls ( $(G i a n n i n i \&$ Albrectsen, 2020).

In sub-Saharan Africa alone, 608,000 additional girls were thought to be at risk of child marriage, and 542,000 additional girls at risk of early pregnancy ( $(S z a b o$ \& Edwards, 2020). In Kenya, the temporary cessation of education services is expected to negatively impact Kenyan girls' life outcomes. In 2020, data from the Kenya Health Information System showed that Nairobi county had the highest incidence of teenage pregnancies with 11,795 in the period January-May 2020 - higher than 2019 figures in the same period where 11,410 cases were reported. From all the counties, the total numbers reported for the period January-May 2020 alone was 151,433 (^Kenya Health Information System 
(KHIS), 2020). Data collected by the Population Council in February 2021 highlighted that pregnancy among girls aged 10-19 years is still a major setback. The highest percentage of girls aged 10-19 years who were pregnant or recently had a baby was in Kisumu (13\%). In Wajir County, 9\% of girls, all of whom were married, were pregnant or recently had a baby, followed by Nairobi (5\%) and Kilifi(4\%) (^Presidential Policy and Strategy Unit (Kenya) \& Population Council, 2021). The above-mentioned challenges demonstrate how continued school and more broadly, learning, is crucial, in particular for girls. Distance learning, especially for the most marginalised learners, has been a crucial element of such continued learning throughout the pandemic and will continue to be important post-Covid-19, to support easier returns to school, minimise permanent dropouts, and provide additional learning for those who cannot return.

Previous studies provide evidence for the promising impact of EdTech solutions on learners in general, particularly when having to learn outside of traditional school settings (^Tauson \& Stannard, 2018; ^Rossing et al., 2012; ^Demirbas \& Demirkan, 2007; ^Banerjee et al., 2007). In the face of Covid-19, EdTech ventures, therefore, made efforts to bridge the gap between learners and access to EdTech. In Kenya, such institutions include KICD, ${ }^{6}$ FunKe, Kytabu, Eneza Foundation, and eKitabu. Furthermore, the Government of Kenya successfully applied for Covid-19 funding ( $\uparrow$ Global Partnership for Education, 2020); the purpose of the funding being to enhance access to online and distance learning for all students in primary and secondary schools and to facilitate a smooth transition in the return to school for targeted vulnerable students. Since the school closures, the MoE and the KICD have been focusing on further developing the existing remote learning system (online and distance learning) to ensure students remain engaged during the Covid-19 school closure period. As such, KICD developed, produced, and disseminated educational programmes through various channels such as radio broadcasting, Education Television (EDU TV Channel), the EDU TV YouTube Channel, and through the Kenya Educational Cloud (e-cloud) (^State Department of Early Learning and Basic Education, 2020).

Contributory efforts by other institutions included: FunKe Science, which moved from physical class sessions to online sessions. They are now a purely remote learning initiative. Kytabu helped caregivers keep up with virtual classroom meetings, and helped them to access all assignments hosted online on their devices, track the learner's progress, and get in touch with the

\footnotetext{
${ }^{6}$ The Kenya Institute of Curriculum Development (KICD) was established by the Government of Kenya on 14 January 2013 under an Act of Parliament - Act No.4 of 2013. Its mandate is to evaluate, vet, and approve the curricular and curriculum support materials for basic and tertiary education, as well as offering curriculum-based consultancy services in basic and tertiary education and training.
} 
teacher easily. They also integrated video calls into their online platform. In partnership with the relevant stakeholders in Kenya, Eneza provided free revision materials to learners to help them pick up from where they left off in school. Learners had access to revision lessons and papers, Wikipedia, and an 'Ask a Teacher' feature either via SMS or online. Moreover, Eneza, in partnership with Safaricom Limited came up with a new EdTech solution, Shupavu291. Shupavu291 allows for access to learning and revision content via text messages and unstructured supplementary service data (USSD).

Nairobi-based eKitabu began featuring a half-hour 'Digital Story Time' across Kenyan TV and YouTube. Each episode featured Kenyan Sign Language (KSL) videos and storybooks designed to help all children continue their learning while schools were closed.

Even though, arguably, there was a high supply of relevant EdTech resources, structural challenges around reaching households and households actually using these resources remained. For example, despite being higher than in neighbouring countries, still only about $75 \%$ of people in Kenya have access to electricity ( $₹$ Common Market for Eastern and Southern Africa (COMESA), 2021), and only 27\% had mobile internet in 2019 (^CSMA, 2020b). Access to digital services is even lower for females in Kenya, with a 34\% digital gender gap ${ }^{7}$ in internet access, and a 5\% digital gender gap when it comes to access to mobile phones ( $\cong$ GSMA, 2020a).

In addition to limiting structural factors, much-less-studied elements such as household norms, attitudes, and behaviours can hinder girls' access, even when the necessary gadgets are available in the home. In a learning-at-home situation, caregivers act as gatekeepers of technology and its educational content. A study by $\uparrow$ Dias et al. (2016) describes it as a fine line between limiting children's rights when exerting such power and the parents' own right to protect their children from (perceived) harm. Girls may be discouraged from accessing or using computers due to social and cultural norms, and are instead expected to contribute more heavily than boys to household chores, care for family members, and family income (^Vodafone Foundation, 2018; IUNICEF, 2016). These entrenched biases have the potential to cause self-regulation of technology. ${ }^{8}$ Some studies have, for example, identified technophobia among girls - a lack of comfort in using technology and accessing the internet ( $\because O E C D, 2018, p$. 22). This discomfort with technology is exacerbated by a number of factors. Among these is a fear of damaging equipment - experienced by caregivers, school principals, and individual learners; further, guidelines about the need to be cautious about internet use

\footnotetext{
${ }^{7}$ The gender gap in mobile ownership and mobile internet use refers to how much less likely a woman is to own a mobile phone (or to use mobile internet) than a man.

${ }^{8}$ I.e., girls may consciously or unconsciously choose not to use technology, because they have been socialised in a community where this was discouraged or at least not encouraged.
} 
or even of mobile phones because of the uncertainty of what is available on these modalities is sometimes communicated alongside a perception that they may be used for inappropriate social purposes (₹Zelezny-Green, 2014).

In 2014, in a multi-country study on social norms and education conducted in Uganda, Nepal, Ethiopia, and Vietnam, communities remained unconvinced that an educated girl makes a better marriage partner, and as such were reluctant to invest in higher education for their daughters ('Watson, 2014). A values study in Kenya also concluded that the combination of cultural beliefs, traditional gender-based division of labour and gender-based violence (GBV) acted as significant barriers to education for girls ( U NICEF Eastern and Southern Africa Region, 2016). Deprioritisation of girls' education, disproportionate burden of household chores, and different expectations around owning or using technology all impact girls' opportunities for technology-enabled learning ( $\Uparrow$ Naylor \& Gorgen, 2020; $: Z e l e z n y-G r e e n, ~ 2011)$. Actual use can be driven by small changes and details, for example, in the

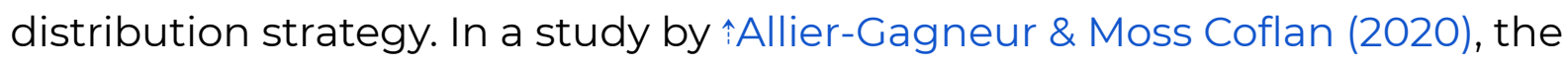
authors find that scheduling broadcasts in the evenings better takes into account girls' workload and preferences. This is the main focus of this study, in which we aim to further understand barriers to girls' access to and use of EdTech at home, particularly in terms of non-structural factors. 


\section{Methodology}

\subsection{Research design and methodology}

As shown in Figures 1 and 2, the project was composed of two distinct phases, a primary research phase and a 'human-centred design' thinking phase.

In the primary research phase (Phase 1), a mixed-methods approach aimed at answering the primary research questions outlined in Section 1.3. It included 58 qualitative interviews as well as 494 quantitative phone surveys with caregivers. Due to time constraints, both qualitative and quantitative interviews were conducted simultaneously. Results from this phase subsequently informed the human-centred design thinking process. This second phase (Phase 2) focused on directly addressing the problems identified during Phase 1.

We chose to conduct all primary research (qualitative interviews, quantitative surveys, and user testing) via phone. The first reason for this was that concerns about further waves of Covid-19 continued to restrict in-person research across Kenya. Second, studies conducted by the 'Busara online' ${ }^{\prime}$ team gave us the confidence that we would be able to collect data of high quality. Finally, it was the most cost-effective approach and allowed us to reach a larger sample than we might otherwise, which in turn increased the precision of our insights.

\subsubsection{Primary research phase}

\section{Desk review}

The primary research phase started with desk research, as summarised in Section 2. Two types of information sources were taken into consideration:

1. Websites of over 20 EdTech companies / organisations in Kenya and East Africa.

2. Academic articles, working papers, and literature that were searched for systematically, using a list of keywords deemed relevant through Google Scholar and the EdTech Hub database. We shortlisted this to 36 applicable articles, which were reviewed and summarised in the literature review.

\footnotetext{
${ }^{9}$ More details on the Busara Online team and their efforts are available at: https://medium.com/busara-center-blog/taking-busara-online-43606914a597 and https://busaracenter.org/covid_19_response/data-collection-in-times-of-covid-1, other than this, results are as yet unpublished.
} 
Reviewing websites of EdTech companies / organisations in Kenya and East Africa was important in order to understand how various organisations responded to the Covid-19 situation, what type of learning material was offered, and what channels were used. Learning about the landscape and existing opportunities allowed us to put our research findings into context.

Figure 1. Overview of the primary research phase.

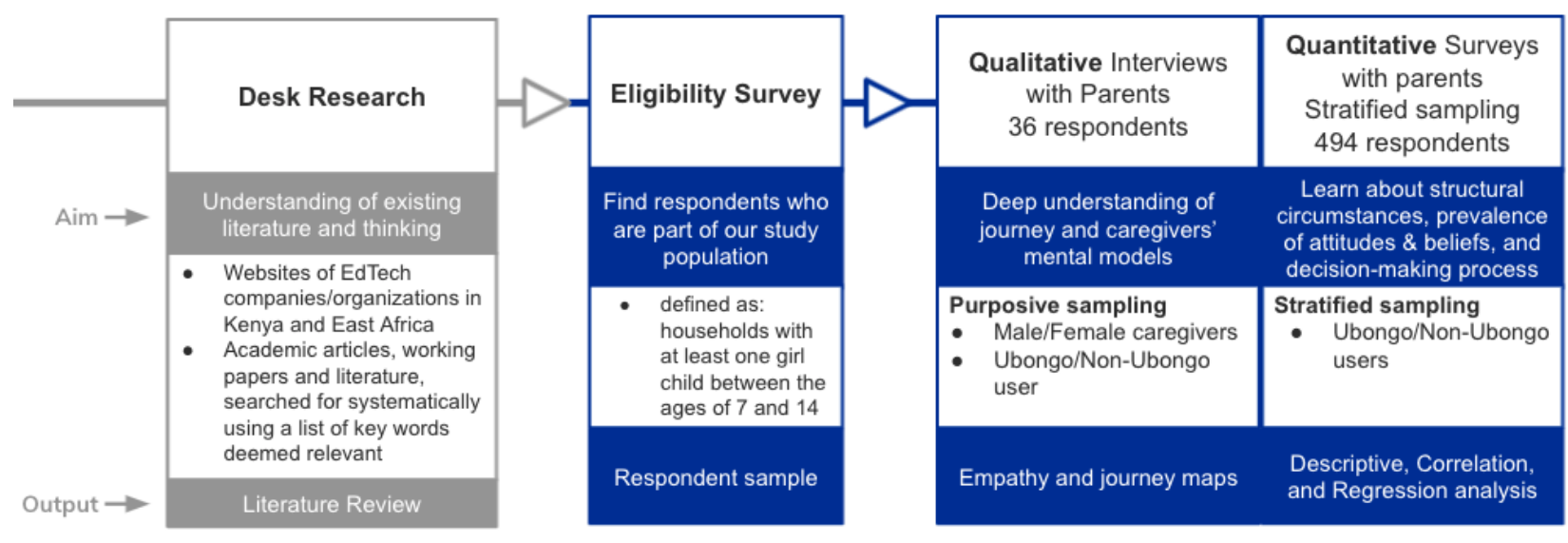

\section{Sampling and eligibility survey}

To maximise the relevance of our study insights and to ensure that we would have a large enough sample to learn about the determinants of girls' EdTech usage, we defined our study population as 'households with at least one girl child between the ages of 7 and 14'. The age restriction was introduced to align with the audience / target group of Ubongo's products.

As such, we were required to first survey participants for eligibility. The respondents of this eligibility survey were drawn randomly from Busara's database of over 88,000 Kenyan households, as well as a list of 900 caregivers provided by Ubongo. The eligibility survey was administered to 1,676 people and led to a final list of 1,075 eligible respondents. In addition to asking about the number of children they had and their ages, we recorded the gender of the caregiver and whether they had regular exposure to Ubongo products for stratification purposes.

From the final list, we chose to draw a purposive sample for our qualitative interviews, in order to balance male / female caregivers, Ubongo and non-Ubongo consumers, as well as households with fewer children versus households with more children. The threshold of less than or equal to two children versus more than two children was determined by looking at the average number of children in our sample, which was equal to 1.94 .

For the quantitative sample, we recognised that more than $92 \%$ of our final list of respondents had regular exposure to Ubongo products, and as such 
decided to stratify on this variable and oversample people who do not use Ubongo products, in order to detect differences and understand potentially varying barriers. Given how widely Ubongo products are broadcast in Kenya across TV, radio and Youtube, we were unable to get a balanced sample across exposure versus non-exposure to Ubongo products. Our final sample was $85 \%$ Ubongo users and $15 \%$ non-Ubongo users.

\section{Analysis}

The analysis of our primary data aimed to be holistic and triangulate between our quantitative and qualitative findings. As such, after a first round of analysis, the team discussed findings and attempted to further investigate open questions or inconsistencies in the data. The following sections explain the initial approach to both the quantitative and qualitative data analyses.

\section{Quantitative analysis}

The examination of our quantitative data primarily revolved around a correlational regression model meant to provide important insights into measurable barriers and levers for access and use of EdTech for girls. It was defined as follows:

Girls' Access / Use of EdTech = Hardware access + Information access + Digital Literacy + Hours spent on chores + Caregiver involvement + Male dominance in decision-making + Caregiver gender norms + Caregiver norms on EdTech + Social norm perceptions + Motivation / Intention + Ability + Opportunity + Demographic Controls

The outcome (dependent) variable was measured in two ways: the estimated number of hours children would theoretically have access to the materials (even if they choose not to use them, i.e., supply-side), and the number of hours children actually used each of the materials (which is the children's own choice i.e., demand-side). Independent variables were numerically constructed indices from one or more survey questions. Details on how these were calculated can be found in Annex 1. Demographic controls included income, the caregiver's education level, whether the household lived in an urban or rural environment, and the household size.

This correlational regression model was then further contextualised with descriptive statistics (histograms, average scores, etc.), in order to better understand the household preferences and dynamics that would lead to certain decisions and behaviours. This included prior exposure and experience with the most popular EdTech tools, distribution of scarce resources, perceived usefulness of resources, considerations when choosing resources, etc. 
Integral parts of this decision model were inspired by the Motivation-Opportunity-Abilities (MOA) model proposed by (^Ölander \& Thøgersen, 1995).

\section{Qualitative analysis}

Qualitative interviews were fully transcribed and translated, and subsequently stripped and entered into a spreadsheet. Transcript pieces were both analysed by respondent for a deep understanding of each household's specific

circumstances, as well as by section for a holistic understanding of trends and patterns across households. Using the method of thematic analysis, transcript pieces were first used to produce codes. From these codes, we then summarised our findings into common themes. These supported our understanding of unique versus common experiences among interviewed households.

One specific section of the qualitative guide - each household member's daily routine during Covid-19 - was primarily used to produce a typical user journey map from the problem onset to the adoption of a potential solution (see Section 4.3 of this report). Focusing on identified barriers and levers during this journey bridged our theoretical insights with the intention of providing guidance for practical interventions.

\subsubsection{Design thinking process}

The findings from Phase 1 (see Section 4) subsequently informed Phase 2 the human-centred design thinking process, outlined in Figure 2 below.

Figure 2. Overview of the human-centred design thinking process.

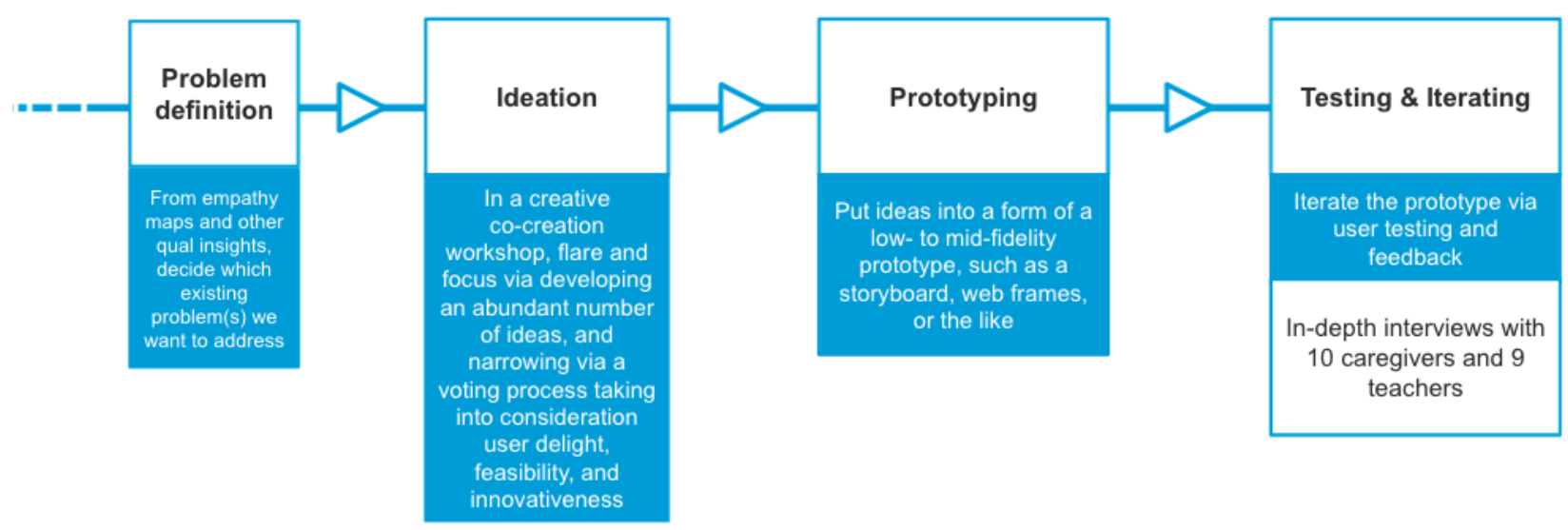

\section{Further analysis}

In preparation for the second phase of this project, we further analysed the data using design-based methods such as persona building and empathy maps. 
From both the quantitative and qualitative data, we identified two characteristics that seemed to significantly influence household experiences with EdTech in rural versus urban locations and in single- versus dual-caregiver households. Considering that product ideation would take place together with Ubongo, we used 'exposure to Ubongo' as a third differentiation variable to explore varying experiences and barriers to "watching Ubongo" in particular. As such, the three personas were defined as:

1. Single mother, urban, does not use Ubongo products

2. Dual-caregiver household, rural, do not use Ubongo products

3. Dual-caregiver household, urban, already use Ubongo products

These personas are 'archetype' characters, which were represented in the data and identified through common patterns, rather than representing actual individual respondents or households.

For each of the three personas, we then completed an 'empathy map' (see Figure 3) to synthesise and focus text-based data around a concept that would allow the team to truly empathise with the people they are designing for.

Figure 3. Empty template of an empathy map.

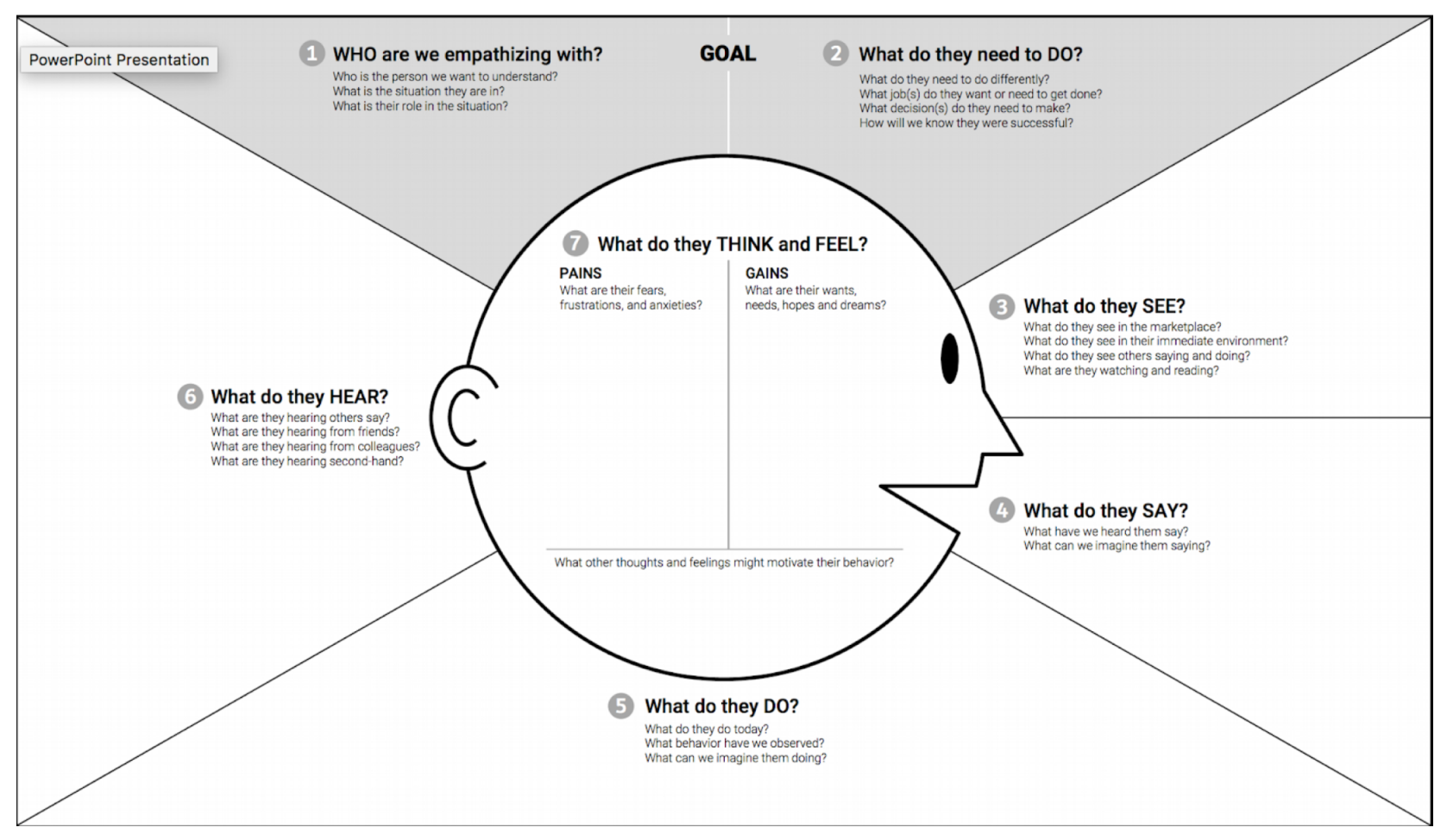

\section{Problem definition}

Based on the empathy maps, quantitative insights, and qualitative thematic analysis, the team proceeded to formulate key problems faced by the 
households in our sample. In the next step, these problems were rephrased into 'How might we...' (HMW) statements, which tend to allow for more creativity and openness when ideating solutions.

'How might we' statements help define and frame design challenges. These questions open up opportunities for design that align with core insights and user needs uncovered in Phase 1 of our research ( $\uparrow$ Dam \& Siang, no date).

'How' suggests that we do not yet have the answer. 'How' helps us set aside prescriptive briefs and helps us explore a variety of endeavours instead of merely acting on what we 'think' the solution should be.

'Might' emphasises that our responses may only be possible solutions, not the only solution. 'Might' also allows for the exploration of multiple possible solutions and not settling for the first one that comes to mind.

'We' immediately brings in the element of a collaborative effort. 'We' suggests that the idea for the solution lies in our collective teamwork. ${ }^{10}$

These HMWs were subsequently fine-tuned using the Ubongo team's feedback. The final HMWs were segmented into two categories:

1. Primary (to encapsulate the defining theme of the design process).

The primary HMW is the one that best captures the considerations laid out in the design challenge and highlights the most salient characteristic of that key population. This HMW will anchor the design process and activities.

2. Nested (to probe sub-themes that upheld the 'main' theme).

Supporting HMWs capture secondary design opportunities and play an important role in completing the primary HMW's. Some nested HMW's may get specific activities in the co-design agenda while others will supplement the primary HMW activities.

The prioritised HMWs for the co-design session can be found below. These were developed based on the insights gained in Phase 1 of the study where we were trying to understand the key barriers to access to and use of EdTech (see Section 4).

1. How might we make supplementary content relevant and accessible to all stakeholders (teachers, caregivers, children)?

${ }^{10}$ Interaction design foundation definition ( 
- How might we make the link between the curriculum and supplementary content clear to all relevant stakeholders (teachers, caregivers, children)?

- How might we make caregivers aware of the different learning materials available free of charge beyond textbooks / printed materials, which can help their children in school?

2. How might we create awareness and demand for digital learning materials?

- How might we create value?

- How might we make digital learning materials accessible? (i.e., what are the structural barriers we need to overcome?) 

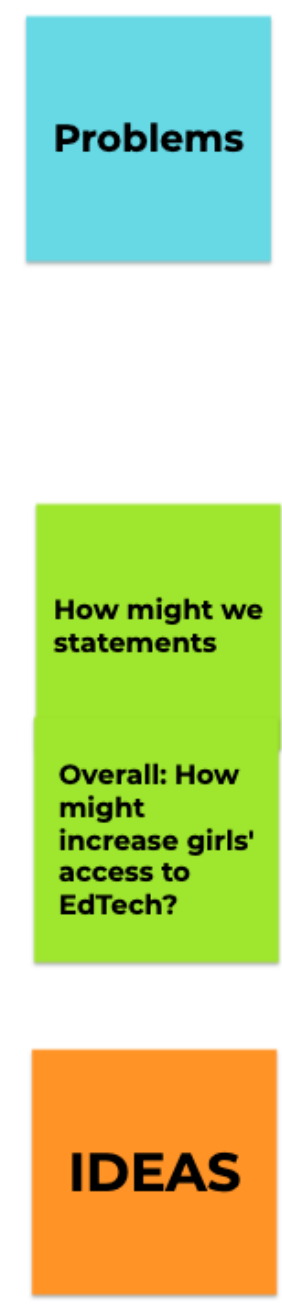
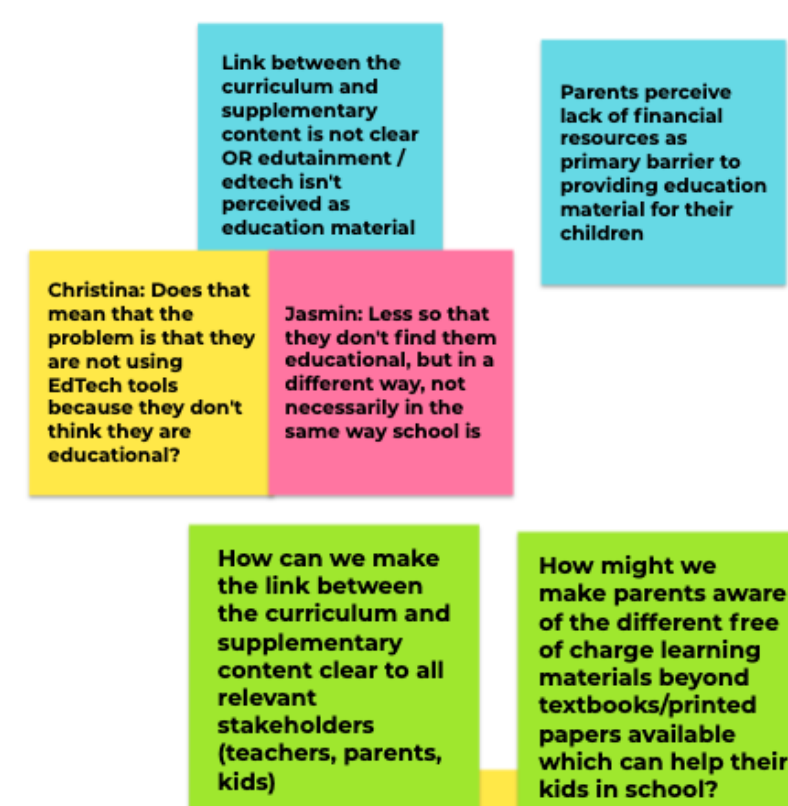
How might we
make parents aware
of the different free
of charge learning
materiais beyond
papers available
which can help their
which can help their
kids in school?

kids)

Could be

combined /

are connected

Teachers: link between what

we are doing

curriculum

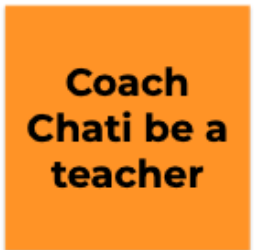

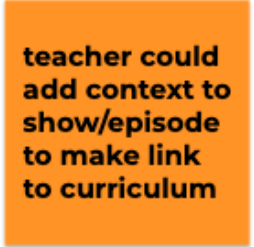

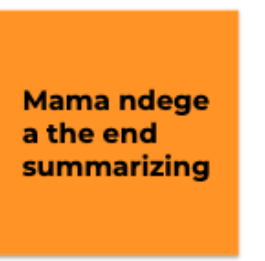

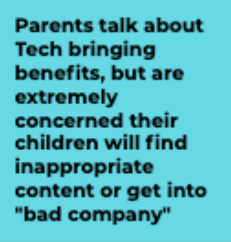

Parents
People are not

EdTech/education

material beyond
classic textbooks/

do not see these
options

How might we

make learning

materials accessible
for girls or all kids? -

too broad. how

might we make

materials

\section{SUPER \\ IMPORTANT \\ BUT \\ POTENTIALLY \\ TO BIC}
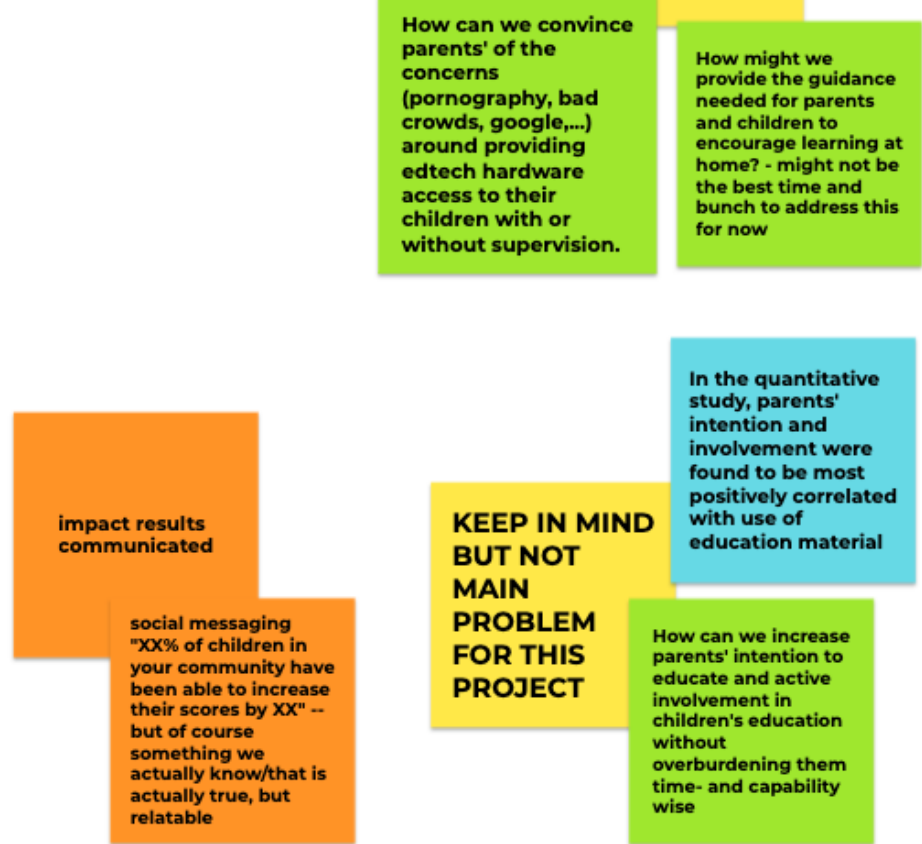

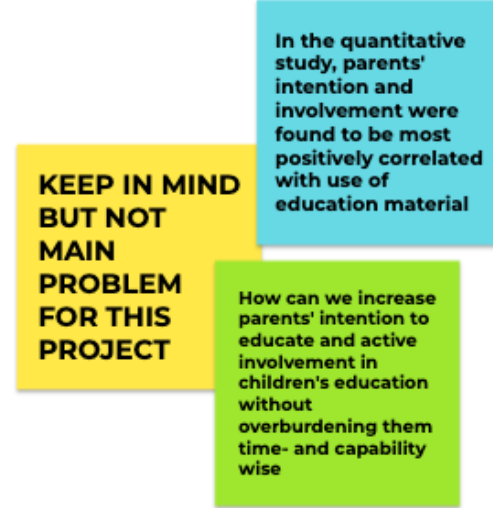




\section{Co-designing}

Co-design means developing processes for understanding, developing, and supporting mutual learning between multiple participants through collective decision-making and collective design ( $\$ S c a i f e$ et al., 1997). The end goal of co-creation is the same as that of research and concept design: to identify a solution that provides users with better experiences, and organisations with improved and innovative services. This collaborative approach promotes constructive reflection and dialogue where all parties involved have equal participation and work together towards a shared goal, as well as give end-users agency to co-design solutions that are aligned with their needs.

The purpose of the co-design workshops with the Ubongo and Busara teams was to ideate and brainstorm ideas based on the refined design challenge or HMW statements.

\section{Approach}

These workshops were intentionally structured to capture the processes that would enable our respondents to reflect, deliberate, and make decisions.

1. Discovery: to build a unified perspective of the landscape, with the Ubongo team, by ensuring an understanding of the background, followed by eliciting the barriers faced by Ubongo. This was to create ownership for co-design of solutions and to generate collective awareness of the challenge.

2. Personal thinking: to encourage individuals to think through the problem by sharing raw, initial ideas for each HMW.

3. Collaboration on ideation and concept building: to synthesise individual outputs from the 'Discovery' and 'Personal thinking' stages by grouping ideas that were similar in concept. These 'clusters' were then filtered into an umbrella idea, which was used to flesh out details for form, content, and channel. To do so, we used specific qualitative probes about what type of intervention can be used to address the HMW as well as specific messaging / content / imagery that should be included in the design of the prototypes, and how it should be delivered.

4. Prioritisation: to select top ideas from the list generated that were perceived as desirable or delightful, impactful, and feasible, by asking participants to rate them using the following quantitative metrics:

a. Desirable or delightful: Voting on ideas that will be the most appealing or delightful to caregivers and teachers. 
b. Impact: Voting on ideas they think will have the highest impact for the specific HMWs that were generated.

c. Feasibility: Voting on ideas that can be prototyped within the time period for testing and which can be easily implemented within the context of the problem.

\section{Concept refinement}

Using the prioritisation inputs from these co-design sessions, the Busara team refined these concepts with a view to validating the feasibility of concepts and aligning concepts with best practices.

The concepts generated were translated into ideas, with multiple variations of visually tangible prototypes that teachers and caregivers would be able to interact with. For fleshing out these concepts, Busara used the following approach:

1. Clustering the prioritised ideas to form themes.

2. Fleshing out clustered ideas by:

a. Adding specifics around how the concepts would work

b. Defining barriers

c. Defining the target audience for the concepts

d. Identifying channels of dissemination

e. Formulating key questions for testing and testing elements within the prototypes.

The finalised concepts were then shared with the Ubongo team for feedback. After the feedback was incorporated, the Ubongo team built them into mid-to high-fidelity prototypes that were used for user-testing employing qualitative techniques.

\section{Prototype testing and validation}

In order to test the prototypes, Busara used qualitative in-depth interviews with both caregivers and teachers to validate the prototypes to obtain indicators of preference, understand motivations behind preferences elicited, and their desirability.

The interviews conducted were to probe the following research questions to better understand the existing prototypes in a greater level of implementation detail. 
1. What are the general impressions of the end-users toward the prototypes?

- What do people like about the prototype (desirability)?

2. What elements of prototypes would drive the uptake of digital learning materials?

- How would the prototype influence caregivers in using supplementary materials (viability)?

3. What components need improvement and would optimise the effectiveness of prototypes?

- What doesn't work / what don't they like about the prototype?

- How easy would it be for caregivers and teachers to access / use it in terms of cost, time, and access to technology (feasibility)?

- What would they like to change about the prototype / how would they improve it?

\section{Data analysis}

We performed a thematic analysis of the qualitative data for the overall sample to identify similarities, and also at a sub-group level, to discern where differences in preference were expressed.

\subsection{Research instruments / tools}

This study used three kinds of research tools - for the primary research phase, a semi-structured, qualitative, interview guide and a quantitative survey were created in an iterative process, integrating feedback from the EdTech Hub team, Ubongo, and information found during the desk research. Earlier drafts were shortened by prioritising questions that would provide new information, rather than specific topics that have been studied recently and / or in a similar context. During the product design phase, a testing guide was created to collect user feedback on several prototyped ideas.

\subsubsection{Research tools for the primary research phase}

The qualitative interview guide aimed to understand girls' learning journeys, surrounding levers and barriers, and caregivers' concerns and perceived needs when it comes to accessing and using educational materials at home. The quantitative surveys, on the other hand, focused more on the decision-making processes, actual behaviour, and norms within households. Using measures for knowledge, attitudes, and perceptions, we hoped to learn what might 
influence girls' access in structural and non-structural ways. They included the following sections, listed in Table 1.

Table 1. Sections of the research tools.

\section{Qualitative interview guide Quantitative survey}

\begin{tabular}{lll}
\hline Section 1 & $\begin{array}{l}\text { Daily routine during Covid-19 } \\
\text { (for each household member) }\end{array}$ & Demographics
\end{tabular}

\begin{tabular}{lll}
\hline Section 2 & $\begin{array}{l}\text { Caregiver support / } \\
\text { engagement in children's } \\
\text { learning at home }\end{array}$ & $\begin{array}{l}\text { Outcomes; final access and use } \\
\text { (i.e., access to and use of EdTech, } \\
\text { household chores, caregiver } \\
\text { support / engagement, children's } \\
\text { demand for EdTech) }\end{array}$ \\
&
\end{tabular}

Section 3 (if applicable)

Ubongo-specific questions

Structural access (i.e., access to hardware, information, specific EdTech providers, digital literacy)

$\begin{array}{ll}\text { Section } 4 & \begin{array}{l}\text { Process of seeking out } \\ \text { resources and deciding which } \\ \text { to provide for children }\end{array}\end{array}$

Other access dimensions (i.e., attitudes, perceptions, ability, opportunity, intention, decision-making power, and priorities)

\begin{tabular}{lll}
\hline Section 5 & $\begin{array}{l}\text { Perceived barriers, differences } \\
\text { between children, and } \\
\text { strategies to overcome these }\end{array}$ & $\begin{array}{l}\text { (if applicable) Ubongo-specific } \\
\text { questions }\end{array}$ \\
\end{tabular}

Section $6 \quad$ Story / Vignette

Section 7 Demographics

Key sections such as decision-making, caregiver support / engagement, and norms around EdTech overlapped in both qualitative and quantitative tools, in order to triangulate and juxtapose the information received from each.

The two main outcomes measured in the quantitative survey were access to and use of EdTech. They were quantified by first asking about specific kinds of

\footnotetext{
"The questions in these sections were asked separately for each child in the household that was between 7 and 14 years old, i.e., they were looped over these children in order to get a more indirect, and therefore more unbiased, measure of access and use for girls versus boys.
} 
material and then estimating the number of hours per week the child has access to or uses these materials.

The 'Story' section in the qualitative interview guide attempted to elicit a genuine reaction and opinions about third-party behaviour, which is typically used to avoid social desirability bias ${ }^{12}$ and receive potentially 'more truthful' statements about what is seen and practised in the community. The story used in the interviews was completely fictional. Details of the story can be found in Annex 2.

Follow-up questions to this story probed for the age and gender of the children in question, opinions about what is happening, and experiences with such behaviour in the respondent's community.

Ubongo-specific sections aimed to provide necessary baseline information for the product design phase of the project.

\subsubsection{User testing guide during the human-centred design process}

In order to answer the research questions outlined further above, we structured our testing interview guide as follows:

- Demographic information

- Feedback on the video prototypes

- Probes on structure, role of the teacher, supplementary materials and books, role of seeing an actual person / teacher

- Feedback on the audio prototypes

- Creating Links between curriculum and Ubongo content

- Feedback on the prototype lesson plan

- Traditional media

- Feedback on posters

- Trust in information source

- Testimonial videos

- Ambassadors/Influencers

\footnotetext{
${ }^{12}$ Social desirability bias is the tendency of survey respondents to answer questions in a manner that might be viewed favourably by others / the researchers ( $\hat{K}$ rumpal, 2013).
} 


\subsection{Stakeholders}

Busara worked closely with the Ubongo team throughout the duration of the research project to ensure that any research findings could be directly incorporated into their edutainment content in Phase 2 of the project to increase the reach and inclusivity of their shows. There were regular discussions and input from the EdTech Hub team throughout the duration of the study. Further, our results will be disseminated to a larger stakeholder group, including education policymakers in Kenya - primarily the Ministry of Education and education practitioners, with a particular focus on non-governmental and civil society organisations (NGOs and CSOs) and education researchers.

\subsection{Ethical considerations}

For this research, we followed Busara's Research Ethics Policy and Procedures, as well as our safeguarding policy. A Kenyan research permit was obtained for the study from Strathmore University. Due to the remote nature of the data collection for both the qualitative and quantitative activities, consent for participation in our study was obtained verbally from all caregivers and teachers, prior to the commencement of any research activities with them. We ensured that we had an easily understandable informed consent process with a strong emphasis on a respondent's right to terminate the research process at any time, with no adverse impact.

All our research instruments were translated into the local languages that were most appropriate for our sample. To ensure the translations were fit for purpose, we underwent a process of translation and back-translation, as well as conducting a pilot to check for comprehension, length of instrument and framing / suitability of any potentially sensitive questions prior to the commencement of the full study. Our data collection processes are also designed to be as inclusive as possible — we used both male and female enumerators with training in and experience of using inclusive research practices. Where relevant, data collection was led by women to ensure that female participants felt comfortable sharing their experiences and perspectives openly.

\subsection{Challenges and limitations}

The following challenges were faced during the study design and data collection.

- Length of research instruments - our study was ambitious in its remit and the number of research questions that it was looking to answer. As 
such, when designing both our qualitative and quantitative research instruments, we found that at the draft phase they were both very long and would take a substantial amount of time to administer. Given the additional challenges of remote data collection i.e., interviews and surveys being conducted over the phone, it was vital that we reduce the length of the instruments significantly. This required us to narrow our focus to a specific set of research questions and deprioritise others (as mentioned above in Section 1.3.) by identifying what we believed was going to be new knowledge.

- Difficulties in reaching sampled respondents - as our data collection was conducted over the phone, we faced higher non-response rates than we typically would when conducting in-person recruitment. Common challenges experienced included phone numbers not working, phones being switched off, and respondents being unavailable to take part in the research.

Specific limitations to our study included common constraints of phone surveys, sample representativeness, and lack of causality.

As mentioned above, we chose to complete all surveys via the phone for budgetary reasons as well as due to the ongoing Covid-19 pandemic. While drawbacks of surveying on the phone are typically negligible with a well-designed questionnaire, there are several factors that may reduce data quality. First, people may be in an unsuitable environment and unable to concentrate during the call. Second, the survey needs to be shorter than an in-person interview can be and it is not possible to pick up on body cues. Third, related to the following limitation, sample randomisation is imperfect because it is necessary to sample from a list of contacts we have phone numbers for instead of using a random walk method. This influences the representativeness of our sample, which in our case is slightly skewed towards low-income households in urban areas. Arguably, this was not an issue, given that we were primarily interested in learning about barriers and levers for low-income households, however, it must be considered when drawing country-wide conclusions.

This cross-sectional survey is furthermore unable to provide any sort of causal evidence. All quantitative insights presented in this report are purely correlational. 


\section{Results}

\subsection{Sample description}

The final dataset included transcribed and translated text from 58 interviews (39 during the primary research phase, and 19 more during prototype testing), as well as quantitative responses from a total of 494 respondents, with individual data on 929 children (65\% female, 35\% male).

As can be seen in Figures 5 and 6 below, the caregivers in the quantitative sample were $69 \%$ female and primarily between the ages of 30-39. Having worked with existing databases, our sample was skewed towards urban settings, specifically Nairobi. Within other counties outside of Nairobi, respondents were almost exclusively rurally based (see Figure 7).

Figure 5. Gender of respondents.

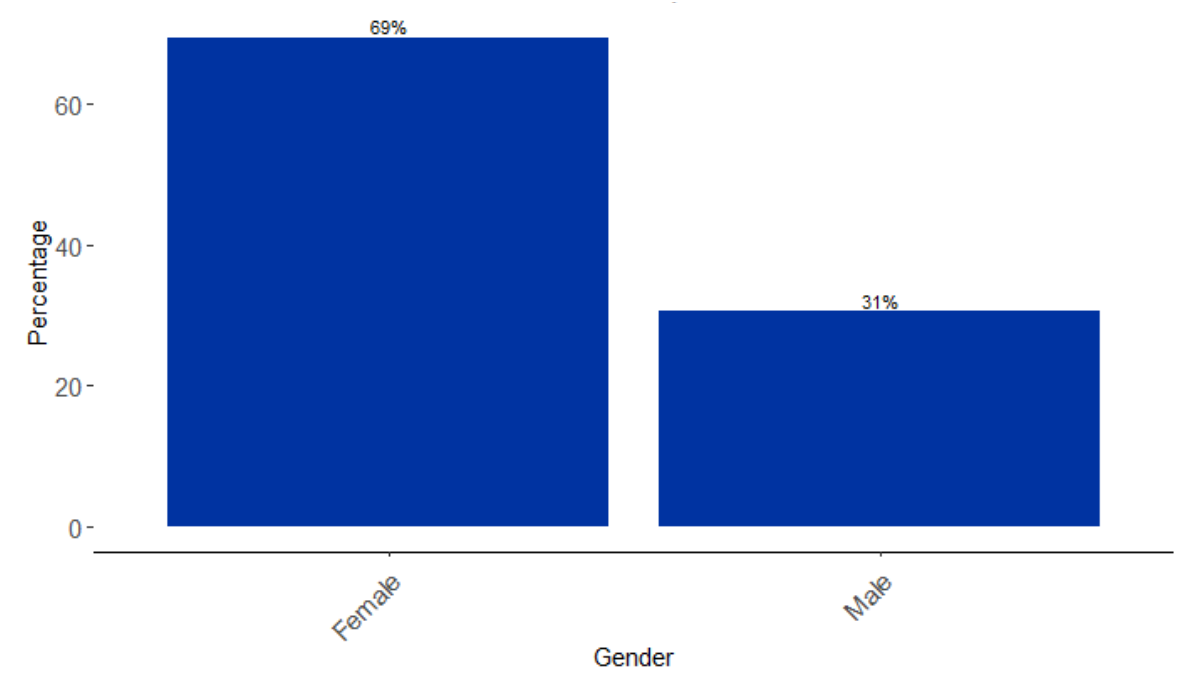

Figure 6. Age of respondents.

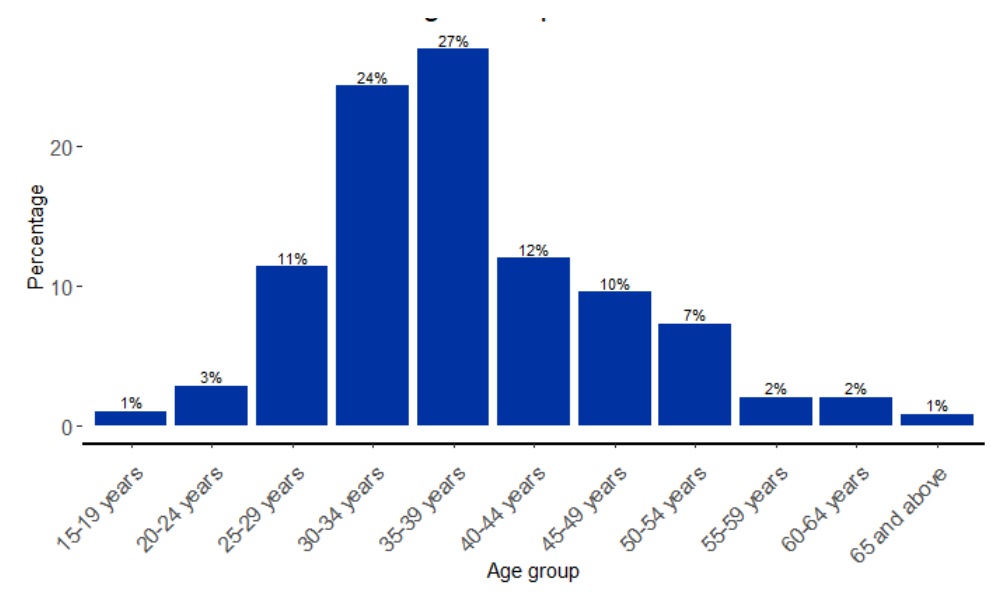


Figure 7. Location of respondents.

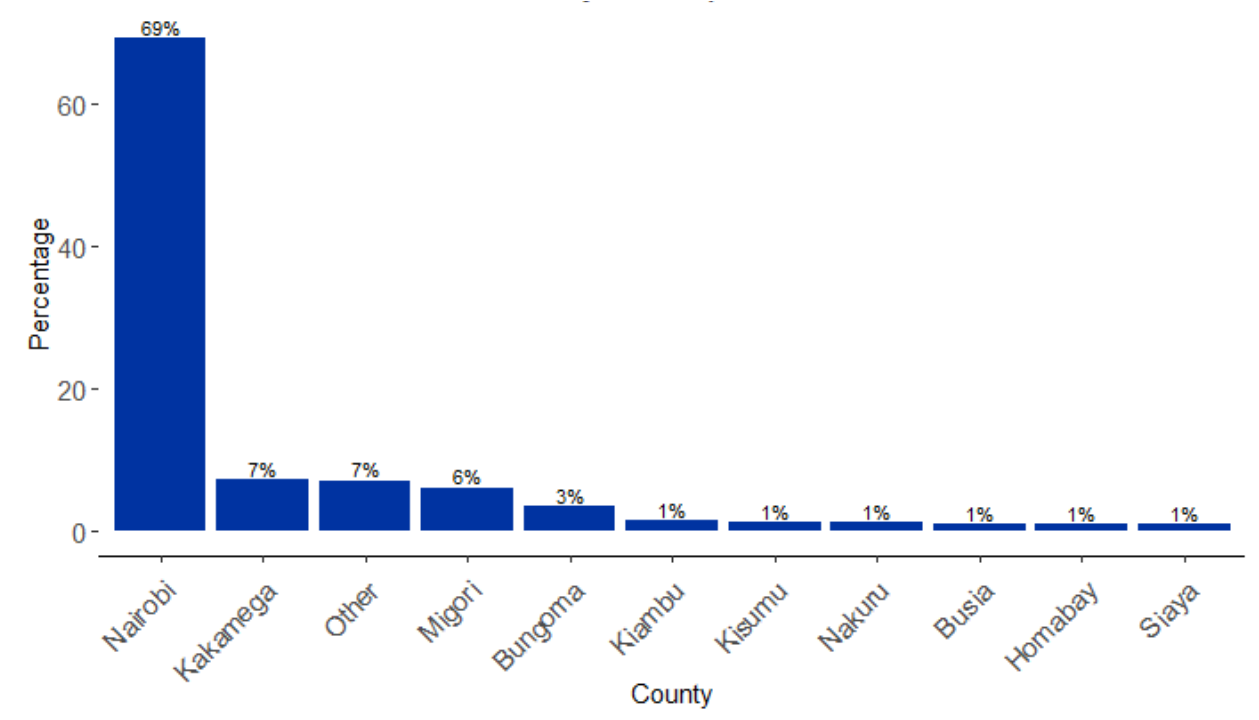

For our targeted population of low-to-medium-income households, educational attainment and income were comparably well spread.

Respondents who were defined as having 'completed primary' and having 'a monthly income of 12,001-50,000 Kenyan Shillings (KES)' were the most represented brackets (35\% and 29\% respectively, see Figures 8 and 9). 
Figure 8. Education levels of respondents.

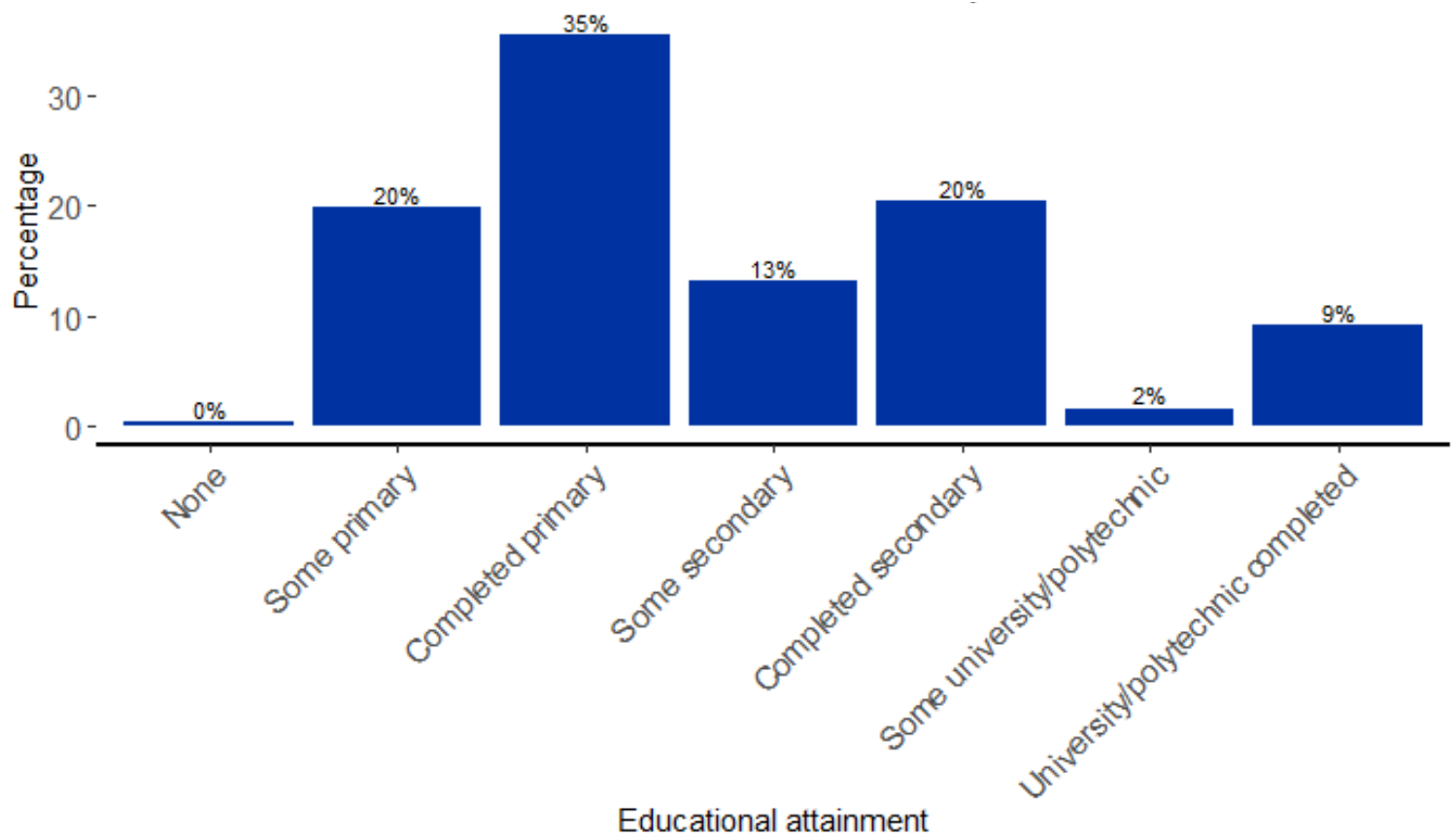

Figure 9. Income levels of respondents.

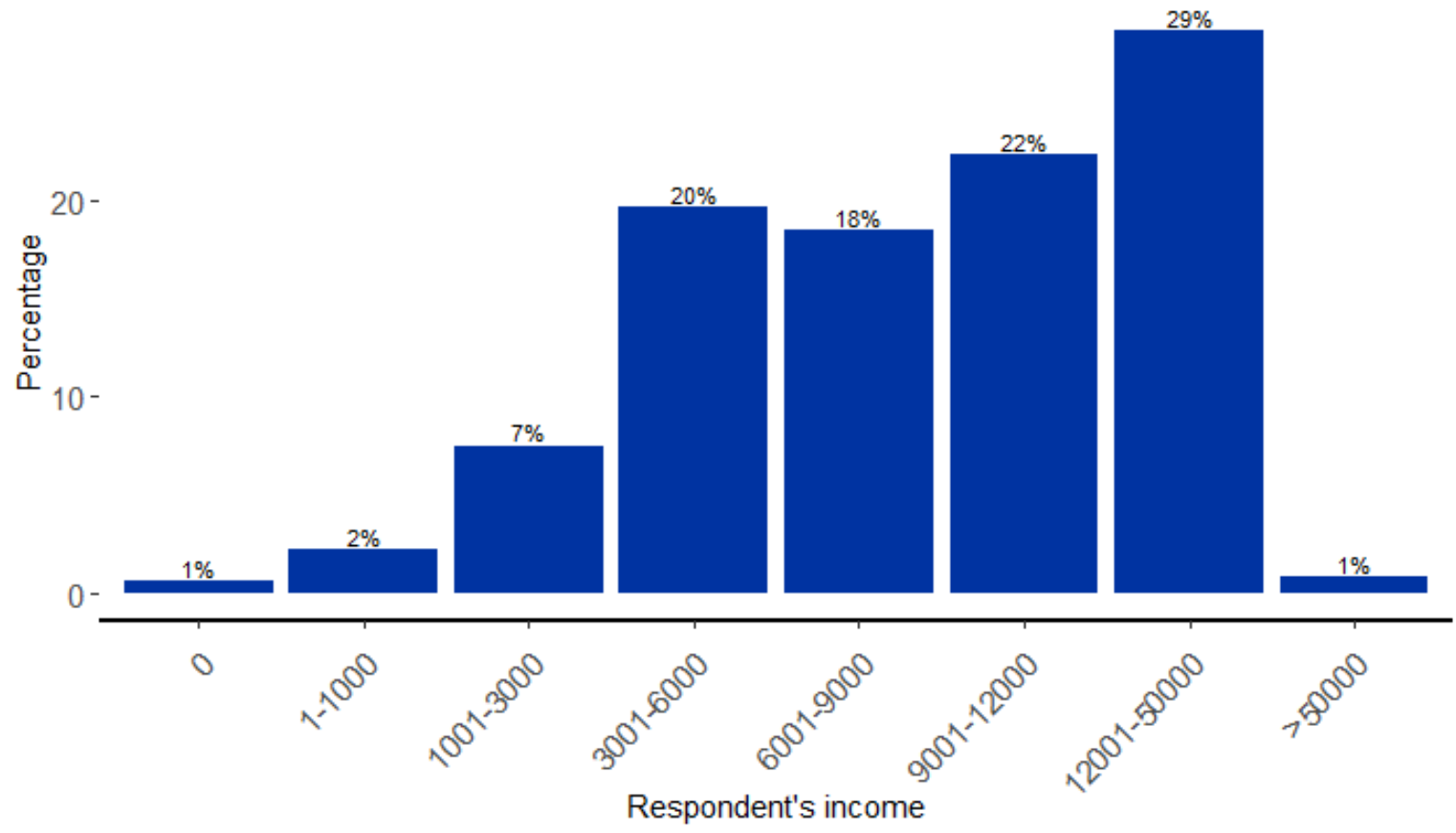

In our qualitative research sample, more than half of the families of respondents engaged with Ubongo products and the sample was skewed towards low-income settings. A majority of the families who engage with Ubongo products have children who are 9 years or younger. In the majority of 
households, both parents lived at home with their children, although we did speak to 7 single-parent households ( 6 female-headed, 1 male-headed). Almost all households preferred communicating in Swahili rather than English and earned their income from informal sources.

\subsection{Barriers and levers improving access to and use of EdTech}

Barriers to access and use are complex, but caregivers' digital literacy, involvement, norms about technology for education, and intention to educate all children are the most promising levers to improve access and use of EdTech.

\section{Key findings}

- Access to educational material, including EdTech and print material, is driven primarily by caregivers' digital literacy, caregiver involvement, male dominance in decision-making, and caregivers' intention to educate their children.

- Access to educational material is significantly negatively correlated with gender norms and household size.

- These drivers remain the same when we consider access to EdTech only, except that the negative correlation with gender norms is not significant.

- Use of educational material generally, and EdTech specifically, is driven primarily by caregivers' digital literacy and involvement.

- Norms on EdTech appear to be the primary barrier to usage.

- Key barriers to access and use based on our qualitative study include:

- Perceived affordability - caregivers believe that the only way they can provide learning materials is through buying textbooks, which can be expensive. As such, caregivers perceive their ability to support their children's education to be limited by affordability.

- Guidance - caregivers also felt unable to guide their children and wanted more professional advice. This is in terms of lesson planning, knowing what materials to use, and a desire for someone to direct their children's questions to.

- Information penetration - there is a perception that not enough learning materials are available, potentially driven by caregivers not considering most EdTech content as 'proper' educational material.

- Norm dissonance - most respondents value and intend to educate boys and girls equally themselves. However, in low-resource settings and when considering the views and actions of their wider communities, caregivers see boys' education being prioritised over girls. This is the same for access to EdTech.

Our first research question asked about which barriers exist and are particularly hindering for girls to access and use EdTech, both structurally 
(access to infrastructure / devices) and in terms of social norms / attitudes / beliefs.

According to our model, as described in Section 3.2, we find significant correlations for a number of variables, however, the importance of specific variables differs greatly depending on whether we look at access or actual use.

As can be seen in Table 2, access to any type of educational materials (including books and paper-based materials) is mainly driven by the caregiver's digital literacy, male dominance in decision-making, and the caregiver's intentions to educate their children (considering a significance level of $a=0.05$ ). As might be expected, it is significantly negatively correlated with gender norms, and also with household size; the former representing the most important attitudinal barrier, and the latter one of the most important structural barriers. These patterns remain very similar when looking strictly at 'EdTech', i.e., excluding paper-based materials (regression 3), except for the fact that the gender norm correlation does not appear to be significant.

Increasing access is vital, yet not sufficient to ensure better learning outcomes - only through actual engagement can children benefit from the opportunity. According to our regressions, using 'hours various education materials were used by the child' as the outcome variable, drivers for actual use of education materials are similar to access when it comes to the caregiver's digital literacy and caregiver's involvement. Differently to access, for actual use of education materials and EdTech, norms on EdTech seem to play a larger role for use and are correlated negatively in both cases (all education materials and just EdTech).

In three of the four regressions, we find a positive correlation between household chores and use / access of education materials, which seems counterintuitive. It may be explained by the general activity level of the child, or increased caregiver involvement in households where children help out more, although for the latter suggestion we find a very low correlation between these two variables (cor $=0.02$ ). Moreover, in both access regressions, there is a negative correlation with the caregiver's perceived ability. ${ }^{13} \mathrm{We}$ might hypothesise that caregivers who believe they know what resources exist and are useful for their children are more targeted in the way they provide access to these materials. Nonetheless, these are findings that should be further explored in future studies.

\footnotetext{
${ }^{13}$ Regarding the caregiver's understanding of what learning resources exist, and which ones of those that exist would best help their children learn. See the specific survey questions in Annex 1.
} 
Table 2. Regression analysis, broad definition of 'EdTech' including printed materials and narrower definition (excluding paper-based materials).

\begin{tabular}{|c|c|c|c|c|}
\hline & \multicolumn{4}{|c|}{ Dependent variable: } \\
\hline & $\begin{array}{l}\text { Access to educ. material incl. print } \\
\text { (1) }\end{array}$ & $\begin{array}{l}\text { Use of educ. material incl. print } \\
(2)\end{array}$ & $\begin{array}{c}\text { Access to EdTech } \\
\text { (3) }\end{array}$ & $\begin{array}{l}\text { Use of EdTech } \\
\text { (4) }\end{array}$ \\
\hline Hardware access indicator & $\begin{array}{r}-1.414^{*} \\
(0.837)\end{array}$ & $\begin{array}{c}0.220 \\
(0.135)\end{array}$ & $\begin{array}{c}-0.365 \\
(0.411)\end{array}$ & $\begin{array}{l}0.268^{* * *} \\
(0.092)\end{array}$ \\
\hline Information access indicator & $\begin{array}{c}-0.216 \\
(0.306)\end{array}$ & $\begin{array}{c}0.038 \\
(0.049)\end{array}$ & $\begin{array}{c}-0.117 \\
(0.150)\end{array}$ & $\begin{array}{c}-0.037 \\
(0.034)\end{array}$ \\
\hline Digital Literacy & $\begin{array}{l}0.704^{* *} \\
(0.306)\end{array}$ & $\begin{array}{l}0.146^{* * *} \\
(0.049)\end{array}$ & $\begin{array}{l}0.359^{* *} \\
(0.150)\end{array}$ & $\begin{array}{c}0.056^{*} \\
(0.034)\end{array}$ \\
\hline Hours spent on chores & $\begin{array}{l}1.081^{* *} \\
(0.539)\end{array}$ & $\begin{array}{l}0.361^{* * *} \\
(0.087)\end{array}$ & $\begin{array}{c}0.273 \\
(0.264)\end{array}$ & $\begin{array}{c}0.122^{* *} \\
(0.059)\end{array}$ \\
\hline Involvement indicator & $\begin{array}{r}-0.542^{*} \\
(0.315)\end{array}$ & $\begin{array}{l}0.259^{* * *} \\
(0.051)\end{array}$ & $\begin{array}{c}-0.090 \\
(0.155)\end{array}$ & $\begin{array}{l}0.239^{* * *} \\
(0.035)\end{array}$ \\
\hline Male dominance in decisions & $\begin{array}{l}1.347^{* *} \\
(0.622)\end{array}$ & $\begin{array}{c}0.163 \\
(0.100)\end{array}$ & $\begin{array}{l}0.642^{* *} \\
(0.305)\end{array}$ & $\begin{array}{c}0.029 \\
(0.068)\end{array}$ \\
\hline Gender norms indicator & $\begin{array}{c}-1.962^{* *} \\
(0.977)\end{array}$ & $\begin{array}{c}-0.045 \\
(0.158)\end{array}$ & $\begin{array}{c}-0.637 \\
(0.480)\end{array}$ & $\begin{array}{c}0.0001 \\
(0.107)\end{array}$ \\
\hline Opportunity indicator & $\begin{array}{c}-0.733 \\
(0.474)\end{array}$ & $\begin{array}{c}0.058 \\
(0.077)\end{array}$ & $\begin{array}{c}-0.222 \\
(0.233)\end{array}$ & $\begin{array}{c}0.089^{*} \\
(0.052)\end{array}$ \\
\hline Ability indicator & $\begin{array}{c}-1.196^{* *} \\
(0.519)\end{array}$ & $\begin{array}{r}-0.157^{*} \\
(0.084)\end{array}$ & $\begin{array}{c}-0.663^{* * *} \\
(0.255)\end{array}$ & $\begin{array}{c}-0.126^{* *} \\
(0.057)\end{array}$ \\
\hline Intention indicator & $\begin{array}{l}5.134^{* * *} \\
(0.888)\end{array}$ & $\begin{array}{c}0.158 \\
(0.143)\end{array}$ & $\begin{array}{l}1.852^{* * *} \\
(0.436)\end{array}$ & $\begin{array}{c}-0.138 \\
(0.098)\end{array}$ \\
\hline Perception indicator & $\begin{array}{c}-0.306 \\
(1.213)\end{array}$ & $\begin{array}{c}0.247 \\
(0.196)\end{array}$ & $\begin{array}{c}-0.264 \\
(0.595)\end{array}$ & $\begin{array}{c}-0.103 \\
(0.133)\end{array}$ \\
\hline Norms on EdTech indicator & $\begin{array}{c}-1.162 \\
(0.729)\end{array}$ & $\begin{array}{c}-0.306^{* * *} \\
(0.118)\end{array}$ & $\begin{array}{c}-0.355 \\
(0.358)\end{array}$ & $\begin{array}{r}-0.142^{*} \\
(0.080)\end{array}$ \\
\hline Income & $\begin{array}{c}-0.0001 \\
(0.0001)\end{array}$ & $\begin{array}{c}0.00001 \\
(0.00001)\end{array}$ & $\begin{array}{c}-0.00004 \\
(0.00003)\end{array}$ & $\begin{array}{c}-0.00001 \\
(0.00001)\end{array}$ \\
\hline Education lvl of respondent & $\begin{array}{c}-0.375 \\
(0.512)\end{array}$ & $\begin{array}{c}-0.114 \\
(0.083)\end{array}$ & $\begin{array}{c}-0.003 \\
(0.251)\end{array}$ & $\begin{array}{l}0.066 \\
(0.056)\end{array}$ \\
\hline Live in urban setting & $\begin{array}{r}2.778^{*} \\
(1.475)\end{array}$ & $\begin{array}{c}0.270 \\
(0.238)\end{array}$ & $\begin{array}{c}0.902 \\
(0.724)\end{array}$ & $\begin{array}{c}0.255 \\
(0.162)\end{array}$ \\
\hline Household size & $\begin{array}{c}-1.363^{* * *} \\
(0.415)\end{array}$ & $\begin{array}{c}-0.084 \\
(0.067)\end{array}$ & $\begin{array}{c}-0.788^{* * *} \\
(0.203)\end{array}$ & $\begin{array}{c}-0.140^{* * *} \\
(0.046)\end{array}$ \\
\hline Constant & $\begin{array}{l}18.014^{* *} \\
(8.640)\end{array}$ & $\begin{array}{c}1.297 \\
(1.395)\end{array}$ & $\begin{array}{r}7.397^{*} \\
(4.240)\end{array}$ & $\begin{array}{c}1.154 \\
(0.949)\end{array}$ \\
\hline Observations & 593 & 593 & 593 & 593 \\
\hline $\mathrm{R}^{2}$ & 0.119 & 0.166 & 0.091 & 0.206 \\
\hline Adjusted $\mathrm{R}^{2}$ & 0.095 & 0.143 & 0.065 & 0.184 \\
\hline
\end{tabular}

In addition to considering these levers in education interventions, it is important to understand what might prevent caregivers from implementing these levers themselves, given that we find overall norms value education highly. Our qualitative research allowed us to categorise the barriers we identified into four major themes: 'perceived affordability', 'guidance', 'information penetration', and 'norm dissonance'. We discuss these below.

\subsubsection{Perceived affordability}

Related to our ability index in the quantitative study, in qualitative interviews, we further learnt that the caregiver's ability to support their children's education was perceived to be limited, primarily due to financial limitations. A majority of respondents felt immense frustration about their inability to provide access to education materials, but this was driven by the belief that the only way they could provide materials was by buying textbooks. In several of our questions, people repeatedly talked about needing more money to buy more textbooks. Given this basic mental model ("I need money to buy books in 
order to provide educational materials for my child."), respondents then further raised the dilemma they faced between providing for basic needs (food, clothes) versus providing for their children's education.

\section{"Yes I do, I buy books at the market, and I borrow books from other kids around the area. I had to try to find books for my children any way I could."}

\section{- Female single caregiver, 49}

\subsubsection{Guidance}

Similarly, ability seemed to be lowered by a perceived lack of guidance from professionals. Caregivers felt unable to guide their children and were longing for any type of professional advice. Respondents expressed a sincere sense of relief whenever teachers or tutors sent them materials and other information, e.g., via WhatsApp groups. Probably even more than for lesson planning and direction over what material to use, both children and caregivers yearn for a person to direct questions to, as they are worried they themselves may not provide correct or sufficient answers to their children's queries. This last point was also mentioned in the context of educational shows on TV and Radio - if the child was left with a question, there was no opportunity to resolve it.

\subsubsection{Information penetration}

Going into this study, our hypothesis was that caregivers may have been overwhelmed by the large number of EdTech products that were being distributed, often free of charge, during Covid-19. To our surprise, none of our respondents confirmed this hypothesis - available materials were largely classified as "not enough" and "hardly anything". One reason for this view may be that information on EdTech has not reached caregivers. And while it is true that out of the 14 most common EdTech offerings in Kenya, caregivers have on average only heard of 3-4, the most popular ones - Akili and Me, Ubongo Kids, and Shupavu (Eneza) - were known by $96 \%, 93 \%$, and $46 \%$ of caregivers respectively. ${ }^{14}$ Further study of our qualitative data reveals it is likely that caregivers don't consider most EdTech or online offers as 'proper' educational material.

\footnotetext{
${ }^{14}$ Followed by M-Shule (32\%), Kenya Certificate of Primary Education (KCPE) Exams app (eLimu) (31\%), Elimika (KICD) (30\%), and resources on the MoE's website - generally referred to as 'Elimika' or 'Kenya Education Cloud' (28\%). Less than 15\% had heard of each of the seven further resources we asked about.
} 
The most common sources when looking for educational materials were offline - bookshops primarily, but also school libraries, street markets (for cheaper, second-hand material) and neighbours. These sources were of course restricted during lockdowns and, as such, our respondents reported that according to their experience "available resources reduced during Covid-19."

Figure 10. Sources of information.

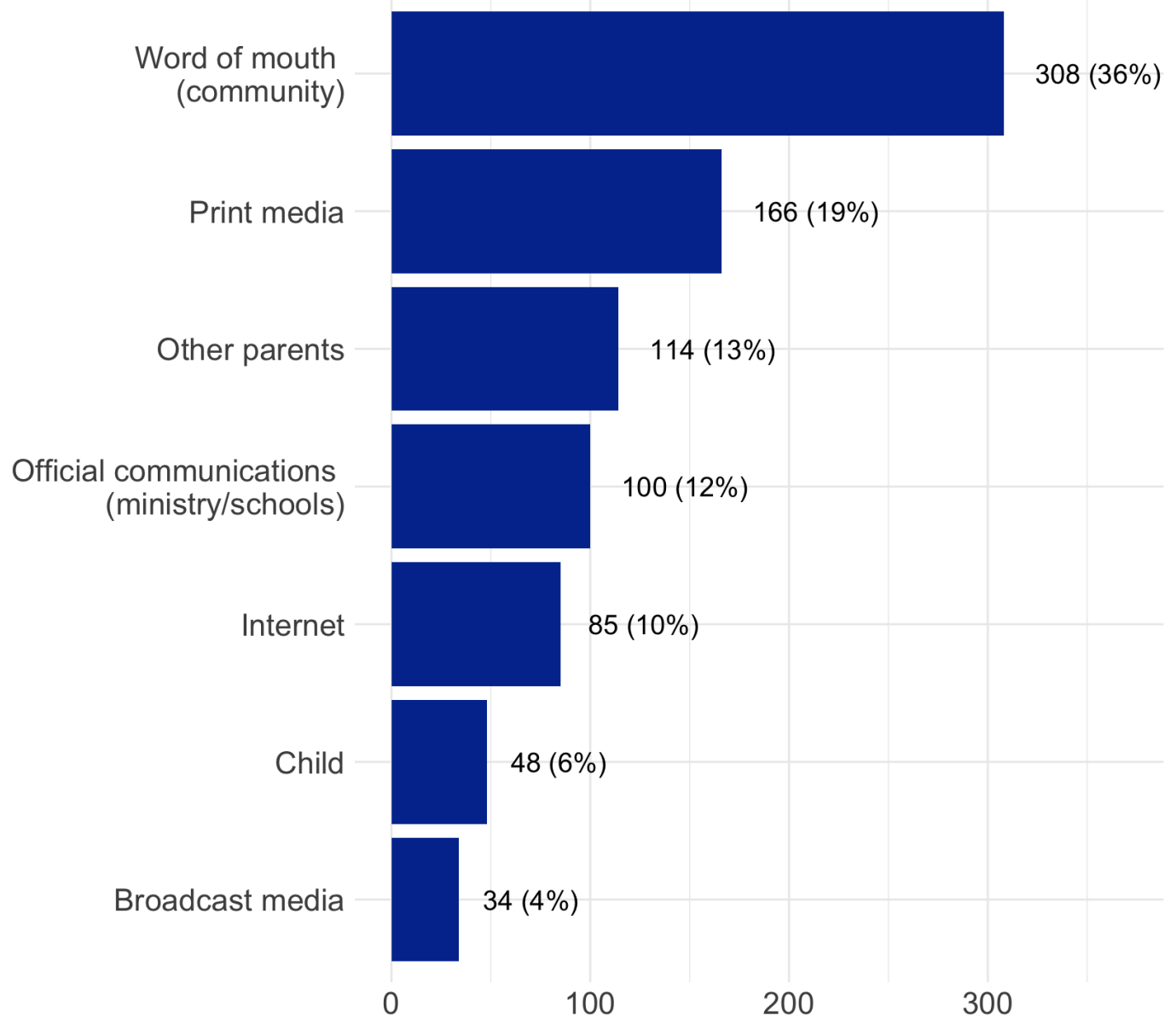

It is unclear why caregivers do not consider edutainment shows, Apps, and other online tools to be a substitute for textbooks. We hypothesise that it may be due to less transparent links to the official curriculum - which, as we discussed below, we find to be one of the most important concerns for caregivers. It would be interesting to further study the seemingly common mental model that only textbooks / printed materials can be considered 'sufficient' for at-home study.

\subsubsection{Norm dissonance}

In both our qualitative and quantitative studies, we were positively surprised that most respondents expressed a sincere intention to, and normative value for, educating both girls and boys equally. Whenever asked about their own 
norms, opinions, and behaviour, they stressed the importance of making no difference based on gender. For example, on a Likert scale from 'strongly disagree' to 'strongly agree', results show an average of 5.3/6 (where $6=$ 'strongly agree') for the statement: "It is important that every child continues to learn during school closures", as well as for: "Girls should be able to learn the same number of hours as boys", and only 3.4/6 for: "During school closures, girls in my community spent less time learning than boys." According to qualitative statements, differences are instead typically made based on age and personality. Where it gets interesting is when we ask about decision-making in resource-scarce situations. In further Likert questions, for example, we get average values of $5 / 6$ for: "If a family has limited resources, the boy should be prioritised in providing access to learning materials/EdTech", and 4/6 for: "Girls should get access to educational materials and EdTech only if they are not needed to help at home."

Our qualitative results, paint a similar picture and provide interesting insights into less obvious or less intentional dynamics. On the one hand, we find a fascinating discrepancy between views of the respondent's own behaviour versus the behaviour of others, or 'society'. In our story, which included one family educating all children equally, and one family prioritising the boy child, respondents unanimously stated that it is not "correct" to prioritise the boy and emphasised that the behaviour of the first family is much more aligned with their own moral stance. When asked, however, whether they see a prioritisation of boys with regard to education happening in their community, respondents again unanimously responded that this is in fact quite common. Disregarding the possibility that we spoke only to outlier families, this finding suggests that individual norms may have already shifted or are in the process of shifting, but community / societal norms are preventing individual families from actually implementing true behaviour change. There is similar evidence from $₫$ Bursztyn et al. (2018) that shows the importance of perceived social norms for actual behaviour, and how correcting such beliefs can make an important difference, particularly when private beliefs are already aligned with the desired behaviour.

On the other hand, even if, in theory, caregivers aim to provide the same educational materials to all children, there may be a significant impact on their children's educational journey based on everyday parenting and exposure. Differences in the distribution of types of household chores $^{15}$ are

\footnotetext{
${ }^{15}$ Even though in our sample the average number of hours spent on household chores is the same for boys and girls at $\sim 2$ hours a day, as well as for how leisure time is spent ("male children spend more time with the father outside of the house, while female children spend more time with the mother in the kitchen").
} 


\title{
EdTech Hub
}

likely to affect longer-term opportunities, i.e., the opportunities that girls deem viable and realistic for them.

Norm dissonance can also be observed with regard to views on EdTech. When asked more or less directly, respondents generally embraced technological opportunities in education - easy access to education, i.e., via TV and smartphones is welcomed both during school closures and in everyday life.

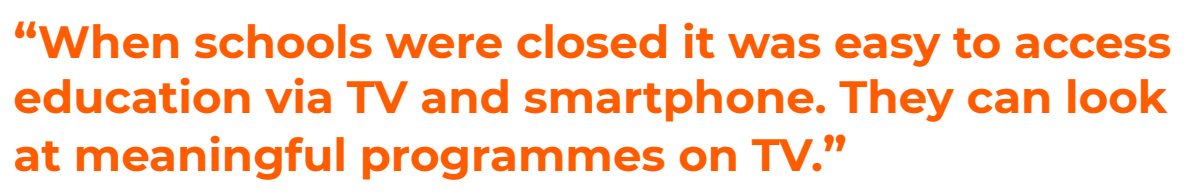

"When schools were closed it was easy to access education via TV and smartphone. They can look at meaningful programmes on TV."

- Male married caregiver, 58

\begin{abstract}
"I tell them the importance of education daily. Tech makes education much simpler for the kids."
\end{abstract}

- Male married caregiver, 37

Yet, when weighing this against the perceived disadvantages, caregivers' concerns in many cases seem significant enough to lead to an outcome in which children end up not being allowed to use EdTech, particularly not without supervision. These concerns included easier access to inappropriate and adult content, which could erode a child's moral compass. Caregivers also felt that their children were not responsible enough to handle devices, or that they were more susceptible to falling prey to unethical online behaviour such as phishing.

The need for supervision, however, reduces the total number of hours children can interact with any sort of smartphone offers, which is one of the most commonly used technologies by EdTech companies and organisations. 


\section{"They can watch TV so much it can ruin their eyes, also some TV content is not for children, as they might start misbehaving like taking alcohol. Also, a kid can use the phone to watch inappropriate content if the parent has not locked them out. Also the overdependence of tech like calculators."}

- Male married caregiver, 33

\subsection{Communicating EdTech compatibility with school curricula to mothers}

Communicating EdTech compatibility with school curricula to mothers via teachers could be a powerful lever to increase EdTech use.

\section{Key findings}

- The female caregiver makes most decisions around children's education in a household as they are seen as having a better understanding of their children's needs.

- There is no uniform way that households distribute learning materials in resource-poor settings. Age and need are some prioritisation factors, while other households emphasise sharing or setting a schedule.

- Compatibility with the curriculum is the most important consideration for caregivers when choosing what learning resources to use.

Caregivers are the gatekeepers of EdTech offerings - ultimately it is their decision what their children receive access to within the household, what money is spent on, and what type of learning is being encouraged or discouraged. As such, we were interested in deeply understanding how caregivers make decisions about encouraging the use of edutainment, smartphones, and low-tech (radio, IVR, USSD, TV) education solutions for their children.

The elements of decision-making we hoped to learn about were:

- Who makes relevant decisions?

- How are scarce resources being distributed?

- What considerations are being made when making a decision? 
- What a typical day looks like to provide context for decision-making.

\subsubsection{Who makes relevant decisions?}

Of all respondents in the quantitative survey, $40 \%$ indicated that if there is only one smartphone / tablet in the house, it is the mother who most often decides who it is used by and when. In $82 \%$ of cases, it would be the same decision-maker for TV and radio.

Figure 11. Distribution of primary decision-makers on smartphone / tablet use.

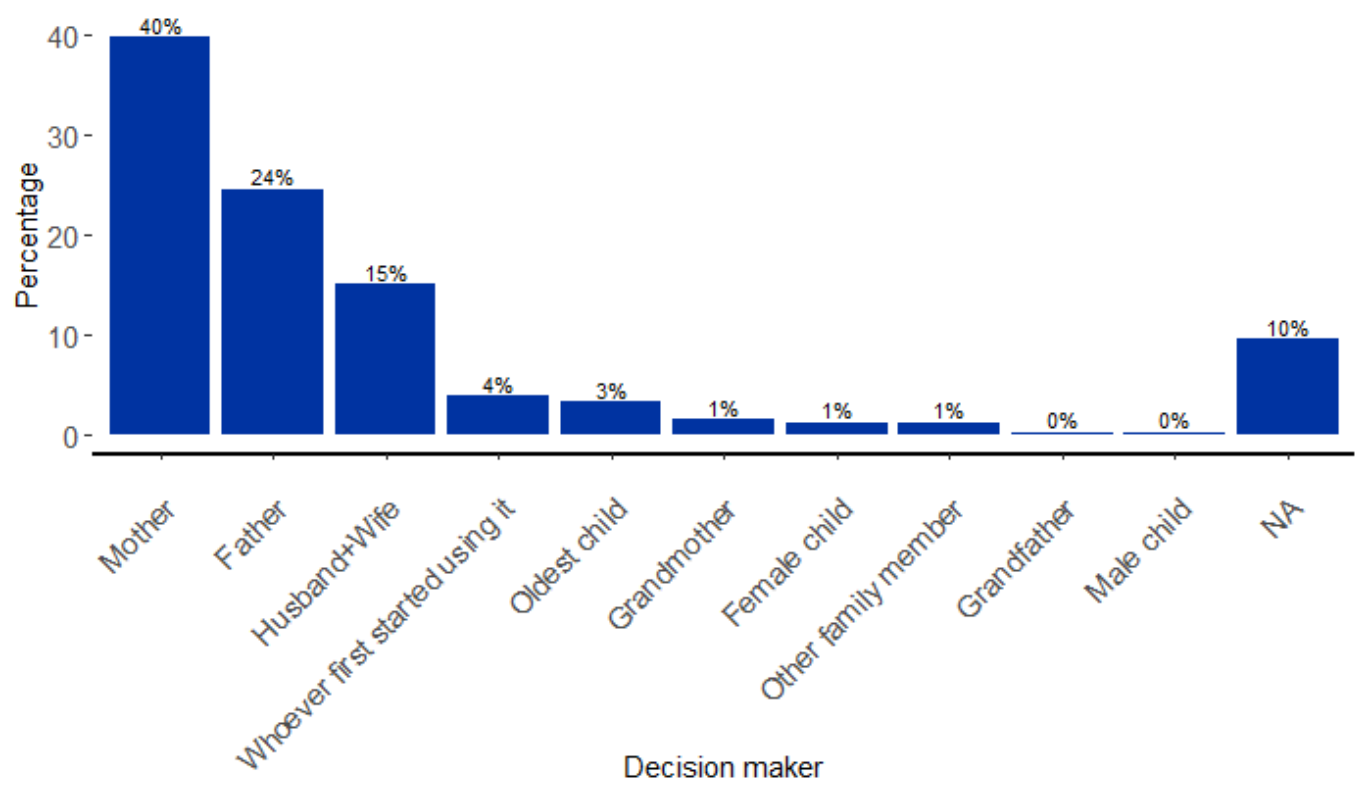

From qualitative interviews, we further learned that the importance of the mother in decision-making is primarily related to the husband being outside of the house more often. Mothers are also deemed as the nurturers in homes and tend to have a better understanding of the needs of their children.

\subsubsection{How are scarce resources being distributed?}

Strategies on how to allocate scarce resources like a smartphone or TV to children differ greatly between the families we interviewed. Several respondents simply named age as the primary prioritisation factor (mostly older children were allowed to go first, although some families reversed this and gave the youngest child priority). Others seemed to allocate them more randomly, i.e., to "who needed it most" or "who wants to use it most" or "who has been a good kid". Sharing was also mentioned quite often, even when it is understood that most material is not suitable for all age groups. Finally, some families found that creating a schedule is the most peaceful and sustainable solution for allocating scarce resources. 


\subsubsection{What considerations are being made when making a decision over learning resources?}

In our quantitative survey, we asked respondents to rank what they consider when choosing the learning resources to use. The option ranked first by most respondents in the quantitative study (46\%) was 'compatibility with curriculum'. Options that were commonly ranked as the second most important consideration included quality, price, and 'how much the child enjoys it'; and commonly ranked as third-most important was 'whether a child could work with it alone'.

In terms of EdTech, caregivers report that they find TV more appropriate for younger children, and smartphones more suitable for older children in more advanced stages of learning.

Figure 12. Caregiver's main considerations when choosing educational resources.

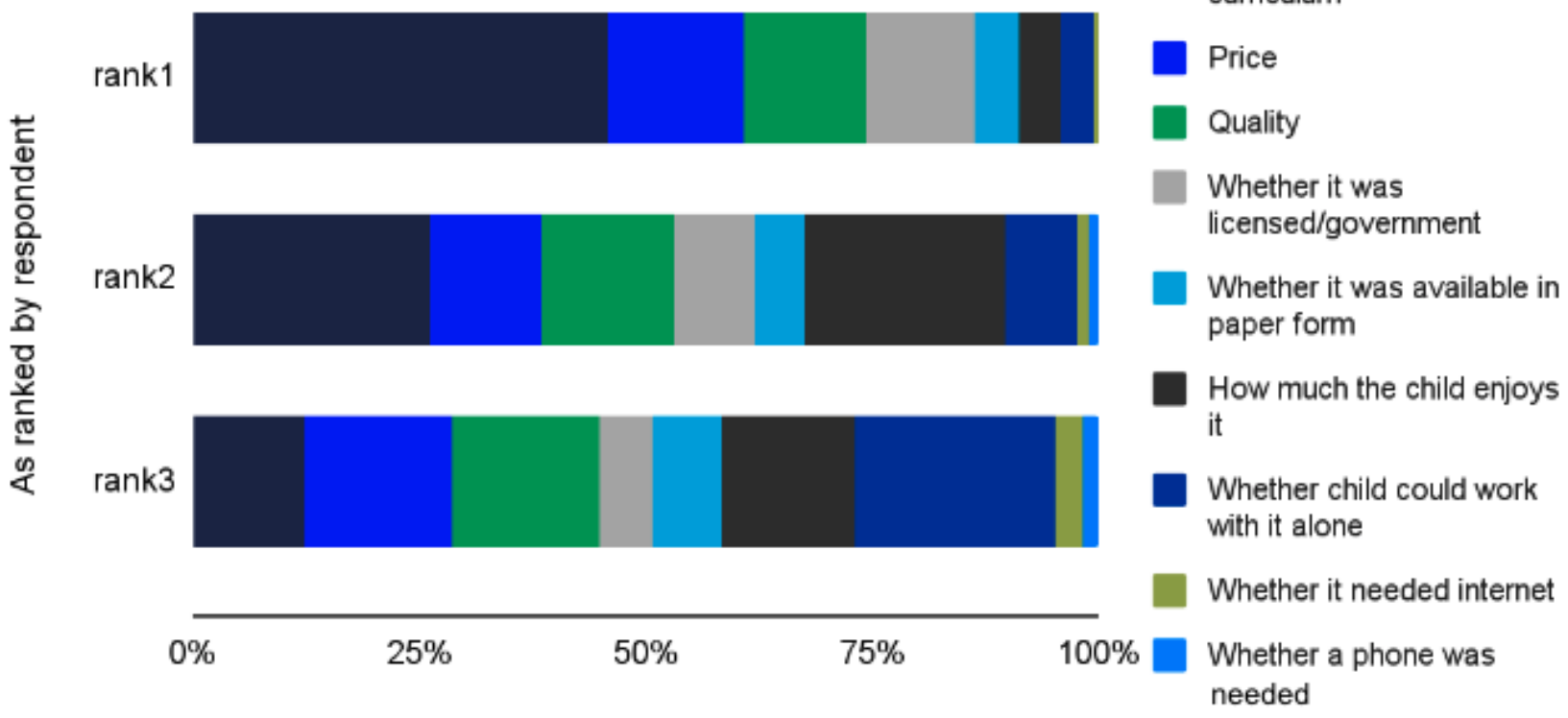

Proportion of respondents

Perhaps more importantly, considerations change over the course of the caregiver's journey towards choosing the right materials (see Figure 12). Qualitative insights show us that when a problem first arises (for example, schools are shut due to the Covid-19 pandemic), the perception that caregivers are lacking the skills and guidance they need motivates them to look for educational material. As discussed above, mental models around what qualifies as 'proper' educational material leave many options invisible. Communicating their value and ensuring ease of use could be considered levers for encouraging higher uptake of EdTech. Before convincing caregivers, financial constraints have to be addressed. Other powerful levers include 
communicating the availability of valuable products by channelling teachers or peer caregivers, mitigating risks beyond a caregiver's control, and designing tools that can be used by children independently without major concerns. If a child enjoys interacting with the material and the links to the curriculum are clear to caregivers, continued adoption and increased learning is then highly likely.

Figure 13. Parents' or caregivers' decision-making journey (drafted from qualitative insights).

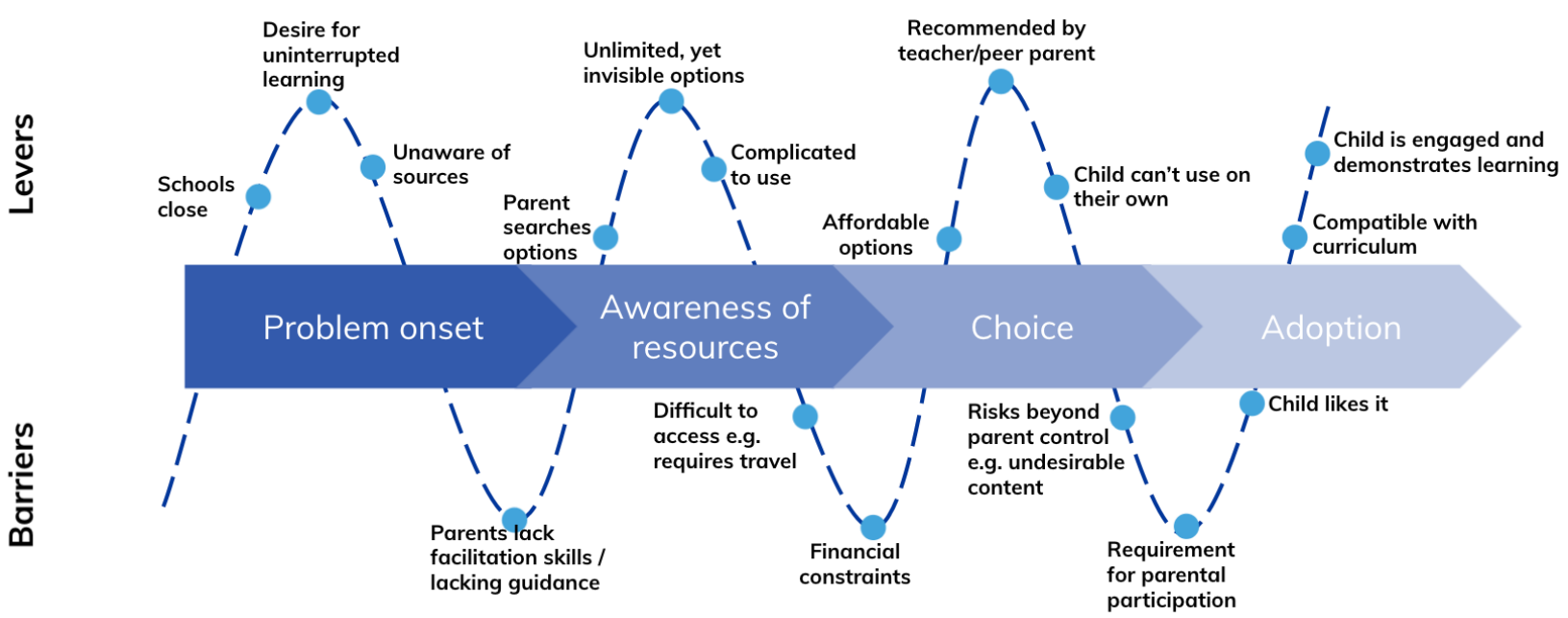

\subsubsection{What a typical day looks like to provide context for decision-making}

In our qualitative research, we asked all of our respondents to take us through a typical day for every household member during school closures. The following paragraphs will describe general patterns and trends identified from these conversations.

\section{Mornings}

In almost all families, the norm is to spend the morning hours on breakfast and household chores. In most families, female children are more likely to perform household chores, whereas male children are more likely to engage in outdoor activities like playing soccer and are rarely indoors. After breakfast, caregivers of rural families tend to go to their farmland, and those in more urban regions to their jobs or the market. Children either join their caregivers (i.e., girls support their mother at the market) or play outside with friends. Mornings are rarely a time for studying. 


\section{Lunchtime and afternoons}

Mothers usually return home around lunchtime to provide a meal for their children. Particularly in single-caregiver households, older children are often entrusted with taking care of the younger children. They sometimes sit together with their siblings to complete some studying during the afternoon or play together. In dual-caregiver households, mothers tend to stay at home in the afternoons, perhaps watch some TV with the children or encourage them to complete educational activities.

\section{Evenings}

The bulk of caregiver involvement and studying was reported to be done in the evenings when caregivers have returned from work. During these hours, families bond over watching TV together, fathers teach or provide guidance on studying exercises, and children are home together to support each other as well.

While this time is typically cherished by caregivers, some of them note that they are not able to provide an ideal study environment, both in terms of infrastructure and nutrition, and that children often complete their tasks in a noisy environment full of distractions. Constant activity by family members as well as the lack of peers and silence significantly reduce motivation and the ability to learn effectively.

\section{"Children need to be in a safe environment and be nutritionally empowered for them to focus on their studies."}

\section{- Female married caregiver, 30}

Interestingly, caregivers made a very clear-cut distinction between playtime and learning time. One lever might be to build on this distinction and encourage the inclusion of learning activities within playtime, which would supplement the more formal learning time later in the day. Alternatively, some caregivers reported that creating clear schedules together with their children motivated them to engage in studying activities independently, even when caregivers weren't around. 


\subsection{Theoretical access to distribution channels}

Theoretical access to distribution channels does not seem to differ between genders, but everyday behaviour and engagement do.

\section{Key findings}

- Our quantitative research shows that there are few significant differences in the distribution of educational resources between girls and boys.

- There are no significant differences between genders when it comes to the usefulness of common EdTech resources.

- However, our qualitative research shows that there is a difference in engagement with educational resources between girls and boys - girls are more likely to enjoy engaging in learning activities but boys are more likely to have access to core educational materials such as textbooks.

Covid-19 has taken a widespread economic toll, particularly on women and girls, exacerbating challenges with their earning power, savings, and access to social protections. This has left younger girls more exposed to harmful cultural norms, gender-based violence, early marriage, and pregnancies. It goes without saying that all these potential challenges pose a great impediment to the continuation of girls' education. In our context, we wanted to understand girls' access to specific distribution channels of educational / EdTech resources in the face of Covid-19.

The major finding in our qualitative research phase is that there is indeed a difference in engagement with educational resources between boys and girls. For instance, we find that girls, generally, enjoy engaging in learning activities more than boys. On the other hand, boys are more likely to have access to academic books, which, overall, is the most accessible resource.

We also see that different developmental stages influence the behaviour of children, which also informs what resources they need and use. Additionally, the majority of the caregivers provide different resources to their children depending on the educational level they are at.

The difference in engagement between girls and boys is supported by our quantitative findings as illustrated below in Figure 14. 
Figure 14. Distribution of resources by male and female children.

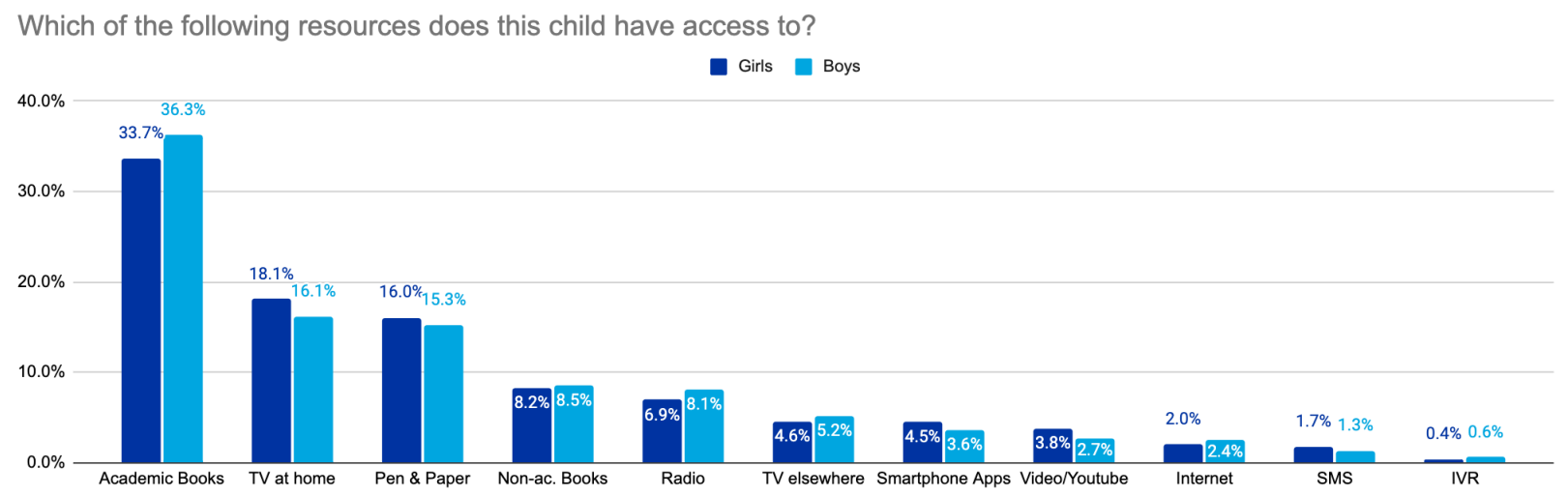

However, overall differences in access seem to be minor and in most cases are not significant. Boys are slightly more likely to have access to academic books - which, overall, is the most accessible resource - and girls tend to watch slightly more TV. Nonetheless, we are not confident that these differences are conclusive or important enough to take into consideration for specific interventions.

Similarly, we do not find significant differences between genders when it comes to the usefulness of common EdTech resources. For both, 'Ubongo Kids' and 'Akili and Me' were named as very important resources and other resources are ranked similarly.

For male children 'Ubongo Kids' and 'Akili and Me' were ranked first by 39\% and $37 \%$ of the respondents respectively, making them almost equally useful for the male children. Female children were inclined towards 'Akili and Me' content. 'Akili and me' was ranked first by $48 \%$ of the respondents compared to 30\% who ranked 'Ubongo Kids' first. Generally, both male and female children found Shupavu (Eneza), resources on the Ministry website, the Kenya Certificate of Primary Education (KCPE) Exams App, and Elimika (KICD) helpful. 
Figure 15. Distribution of perceived usefulness to EdTech resources by male and female children.

How useful was each of the resources for your male children?

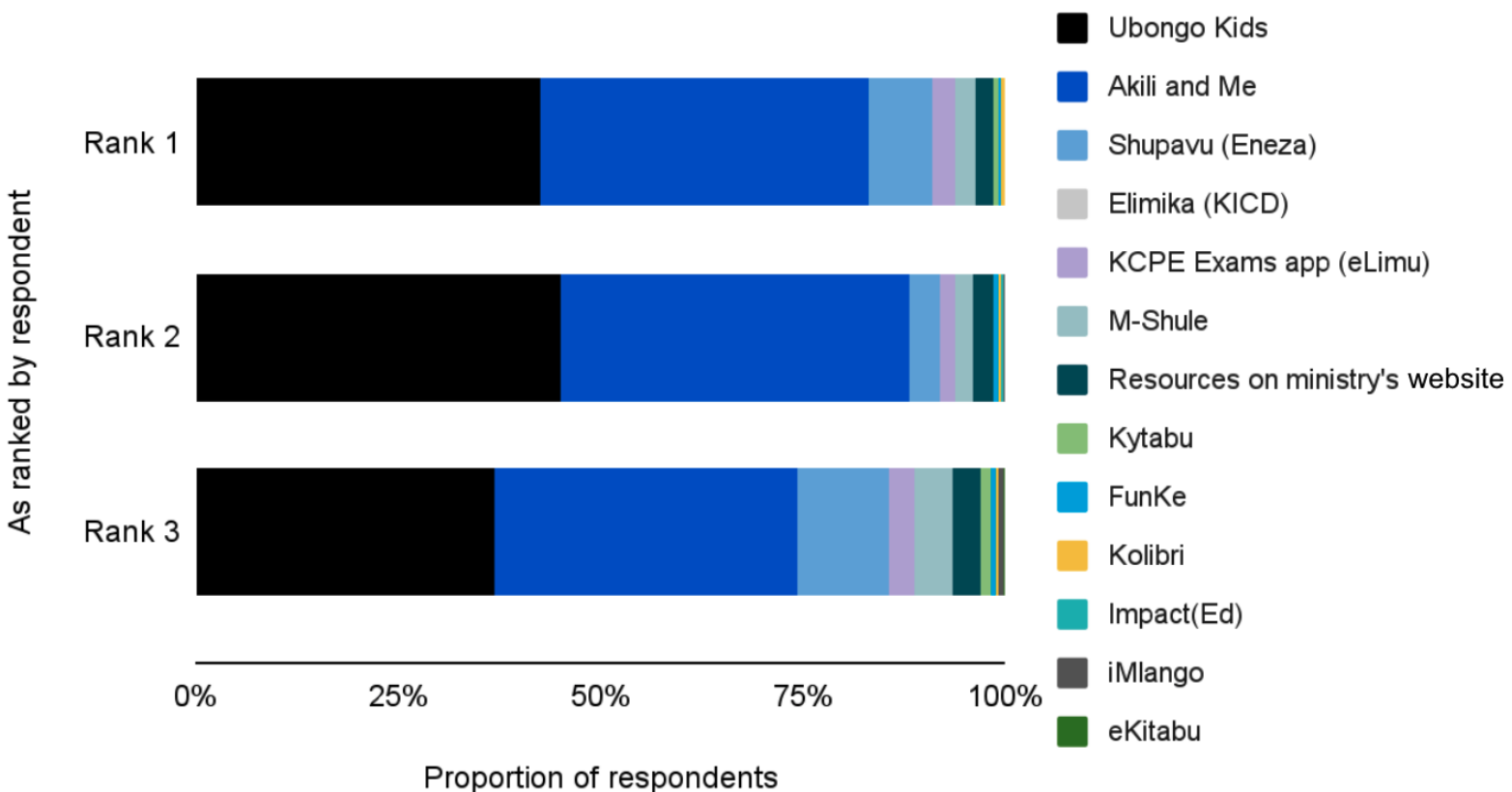

How useful was each of the resources for your female children?

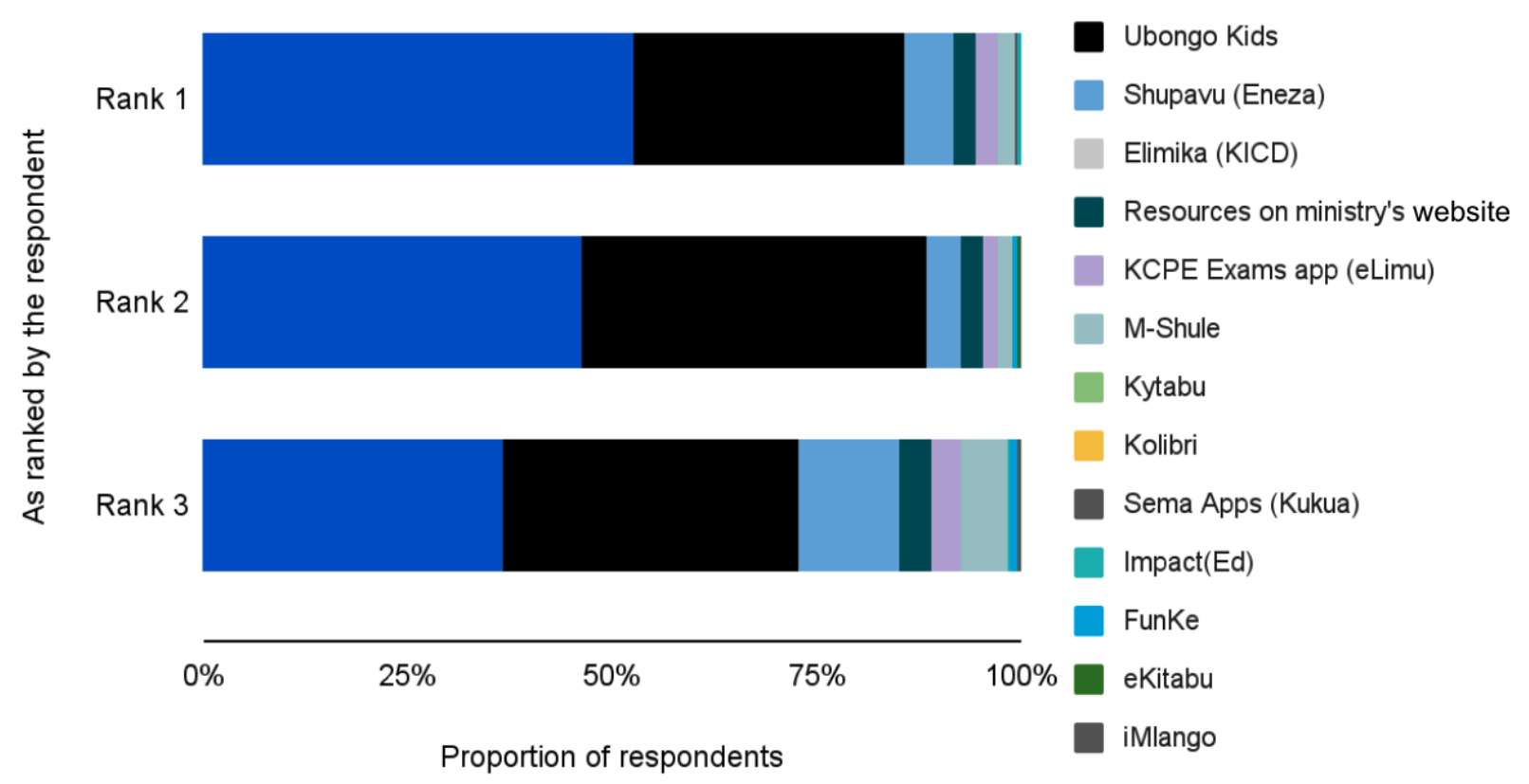




\subsection{Awareness of products beyond TV offerings}

Ubongo's edutainment has already reached many children, however, people are rarely aware of products beyond TV offerings.

\section{Key findings}

- $85 \%$ of our respondents watch Ubongo shows, and of those who do not, $75 \%$ have at least heard of Ubongo, indicating that their reach is very large.

- Awareness of Ubongo offerings beyond the TV show is low.

- TV and mobile phones are the most common modalities used to engage with Ubongo products.

We wanted to further investigate caregivers' perceptions of Ubongo content, their experiences with using Ubongo products, and how they would like to change or improve on Ubongo products. We, therefore, asked respondents about Ubongo's edutainment offerings, and what could be improved to better address the needs of girls and women during Covid-19, in terms of content, access, or usage.

From our qualitative research interviews, it is clear that approximately three-quarters of caregivers were aware of Ubongo products. Interestingly they primarily learnt about Ubongo through their children, rather than any form of advertisement. This was further supported by our quantitative findings that $85 \%$ of our sample watches Ubongo's shows, and out of those who do not already watch them, $75 \%$ have at least heard of the shows. The reach and influence that Ubongo already has within Kenya could be utilised further for learning at home, if amended to address some of the barriers mentioned previously in the findings, such as making the link to the national curriculum more explicit.

Qualitative research findings show that the most common sources of information regarding EdTech resources mentioned were TV and radio. Families that do not engage with Ubongo products cited that reasons for this were lack of awareness that their children did not have ample time to engage with Ubongo, or that they had older children (above the age of 10).

Our quantitative findings, however, show that TV and mobile are the most common sources of information. We also found that awareness of products beyond the TV shows is low. 
Figure 16. Reasons and modalities used for accessing Ubongo content.
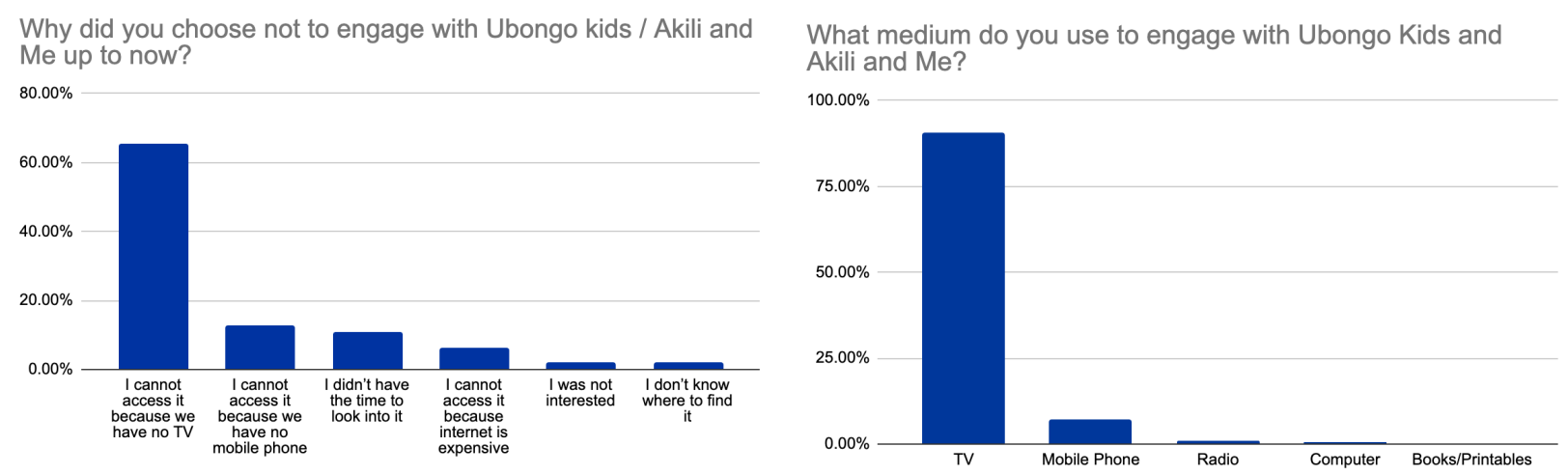

In qualitative interviews, caregivers stated that having access to resources such as stable electricity, TVs, low-cost TV subscriptions, tablets, stable internet connectivity, good health and nutrition would make it easier for the female children to interact with Ubongo products. Families that did not have access to TV had their children visiting their neighbours' houses to watch the programmes as they had noted the frequent programming of the shows and did not want their children to miss out on the content.

Additionally, most children notably finished the tasks - drawing, sewing, maths problems - that were given at the end of the shows, attributing that to the children's genuine interest in the shows. However, a caregiver said having a teacher during the shows to guide the children was necessary to reinforce comprehension.

\subsection{Further insights into secondary research questions and from prototyping testing}

\subsubsection{Insights related to our secondary research questions}

To what extent was the sudden increase in EdTech offerings and materials helpful, and for whom was this closer to an overwhelming choice overload? How can these caregivers and learners be supported in navigating the landscape?

Finding relevant educational material for their children during Covid-19 was undoubtedly a challenge for most caregivers in our study. On a scale from 0 (strongly disagree) to 6 (strongly agree), caregivers responded to our quantitative survey with an average of $4 / 6$ to the statement "It was difficult to understand which learning resources were available for me and my child(ren)", and 3.8/6 to "I did not know which of the existing resources would help my child learn best." 
From our qualitative sample, however, we learnt that respondents unanimously believed that it was not the large number of resources available that confused caregivers - on the contrary, all respondents reported that in their opinion there were too few resources available. Even so, the situation was overwhelming, for three reasons: first, caregivers found it difficult to find resources in the first place, second, they depended largely on voluntary support from professionals (i.e., teachers) to judge relevance and quality, and finally, they struggled with financing the resources that they did find and deemed useful (mostly textbooks).

Does it matter to caregivers whether content / material was curriculum-based and / or licensed or approved by the government during Covid-19?

Interestingly, resources being curriculum-based is incredibly important to the caregivers in our sample. As mentioned above in Section 4.3, it is the number one consideration in decision-making. Moreover, it is the most suggested change to Ubongo's content ("I think it would be great if the content was more aligned with the school's curriculum"). ${ }^{16}$

What type of support is needed to facilitate the use of resources for learning and edutainment through smartphone and low-tech (radio, IVR, USSD) EdTech solutions for girls during Covid-19?

As per the insights from the above two questions, it seems that the two most useful support mechanisms for caregivers would likely be:

1. More guidance from trusted professionals in terms of which resources are relevant and useful for children at what age / stage in their educational path. Trust and professionalism seem particularly key for such advice.

2. Making links between supplementary resources and the curriculum clear and easily understandable for caregivers, in order to make 'less traditional' material more interesting and valuable to caregivers.

These identified needs were considered and discussed during the ideation sessions for the second phase of this study and led to several prototypes, as described in Section 4.6.2.

\footnotetext{
${ }^{16}$ The only response options ranking higher were "I think the content does not need to be changed" and "I don't know Ubongo's content well enough to answer this question."
} 


\subsubsection{Insights from the design thinking process and prototype testing}

The prototypes we developed as part of Phase 2 of the project were as follows.

- Caregiver video testimonials - one with an introduction by a teacher and one without. These videos were developed in both English and Swahili.

- Audio content that contained the same content as the videos.

- A lesson plan, which made the link between the Ubongo content and the national curriculum more explicit.

- Posters, which aimed to pass on information about how other options outside of textbooks, such as Ubongo content, can be used for learning.

\subsubsection{Insights from caregivers on prototypes developed}

Video learning materials

1. Caregivers saw videos as one the best ways to teach children because they are visual and animated, making learning more enjoyable (insight based on the majority of participants). Videos tend to increase the concentration levels of the children, improving content retention.

2. Another perk of using videos for learning is that it is more favourable to the younger children who do not know how to read or write. This is because of the systematic lesson structure and pictorial illustrations in videos, which aid the learning process.

3. Caregivers were generally concerned about the high costs of books but after watching the videos, they became more aware of alternative sources of educational resources for their children such as Akili Kids on YouTube.

Audio learning materials

1. Audios may not garner as much engagement because children are more excited by what they can see compared to what they hear. Caregivers added that the most favourable channels for audio to be shared would be broadcast media such as radio (due to maximum reach) and the internet for Apps such as WhatsApp for easier sharing and downloading. 


\subsubsection{Insights from teachers on prototypes developed}

\section{Video learning materials}

1. Video lessons were seen as really favourable as they were interactive and playful for children and equally seen as an alternative way to ensure children were learning.

2. Teachers see the videos as less expensive for caregivers than buying books, which children ultimately get bored by.

- Of the 5 respondents, 1 uses Ubongo content to aid their teaching, 2 said they would think of including it after seeing the videos, and 1 mentioned that children watched it at home.

\section{Audio learning materials}

1. In general, there was a preference for video over audio, especially if the video was for children: "Because children are likely to lose concentration, you know if they watch, they are keen, there is that instinct because they see the actions but that sitting and listening I don't think it would be more preferable."

2. If audio were to be used, it should be part of radio segments where caregivers can hear it, so it reaches a far wider audience.

\section{Creating links between curriculum and Ubongo content}

1. It was seen as very important to have a direct link of content to lessons.

2. Teachers liked that the lesson plans had direct links to the content and could be used to supplement the school curriculum.

3. Ubongo video content was seen as an easy way to pick up from classroom to home for children as it creates a continuation from school to home.

Some suggested improvements included:

1. Using posters in schools and during meetings between caregivers and teachers to create more awareness.

2. Sending Ubongo content to teachers and caregivers prior to lessons so children have an idea of what to expect from the next lesson, making it easier for them to follow. 


\section{Policy implications}

The policy implications from this study focus on trying to alleviate non-structural barriers to increase access and use of EdTech for girls in Kenya. Table 3 below, outlines the key insights from this review alongside the policy implications.

Table 3. Key insights and associated policy implications.

\section{Key insight Policy implications}

\section{Caregivers lack awareness of EdTech resources as 'proper' learning materials}

\begin{abstract}
While the number of EdTech resources that have been distributed across Kenya throughout Covid-19 may be high, awareness and acceptance of these resources by caregivers is low. Many caregivers perceive traditional learning resources, such as textbooks, as the only trusted form of learning materials and therefore alternatives, such as EdTech materials, remain invisible. This is important, as caregivers highlighted a financial barrier to purchasing textbooks, however, a lot of EdTech resources are free or relatively cost-effective to use. Lack of awareness about the availability of these free, accessible resources is a barrier to EdTech uptake and to learning at home.
\end{abstract}

Increasing awareness through communications campaign support could be an effective way of highlighting the benefits of EdTech and promoting it as 'proper' learning material. Elements of this could be the use of video testimonials that feature fellow caregivers, teachers, and children, as well as community champions.
In our quantitative survey, we asked respondents to rank what they consider when choosing learning resources to use. The option ranked first by most respondents in the quantitative study (46\%) was "compatibility with curriculum'. This link is more obvious with traditional learning resources such as textbooks but is less obvious when it comes to EdTech resources.

The link between the national curriculum and available EdTech resources, therefore, needs to be made more salient. The government has a potentially large role to play in this. 
This could happen through the inclusion of the government logo on EdTech materials, for example, to signify that they have approved the content and that it is in line with the national curriculum; the government may need to work directly with EdTech content producers to create or include supplementary information that makes the link between the content and national curriculum explicit, or it would need to provide guidance to EdTech producers on how best to make the link between the curriculum and their content clearer and more accessible.

\section{Caregivers are seeking more guidance on when / how to use EdTech resources}

We have seen from our research that caregivers have struggled with a lack of guidance when using EdTech. For example, in the context of educational shows on TV and radio, caregivers found themselves at a loss if a child was left with an unanswered question; there was no opportunity to resolve this due to a lack of information and / or the caregiver's lack of confidence in their own ability as an educator. Any support from professionals that is available is largely voluntary and is individualistic and inconsistent.

More guidance from trusted professionals, primarily teachers, in terms of which resources are relevant and useful for children at what age / stage in their educational journey, as well as support in answering questions arising from EdTech content, is very important; The delivery of EdTech resources alone may not be sufficient and needs to be accompanied by a clear source of support for caregivers.

The support could take many forms. In terms of increasing awareness of available and appropriate EdTech resources, the government could develop a database / list of available EdTech resources and the topics / age ranges that they cover. This can be made easily available to all schools and teachers, for ease of passing this on to caregivers and learners directly. For teachers to be able to better respond to questions by caregivers / learners, further training is needed to provide additional support, as well as resource packages developed and made accessible to support answering questions related to EdTech resources if required. Further, the government could work with relevant partners to directly intervene at the caregiver level through digital training to increase their confidence in 
accessing and using EdTech content and training of caregivers by teachers or education providers on how to best facilitate learning at home. Within EdTech, resources could include a chatbot or Q/A feature to answer questions that may arise.

EdTech resources are currently primarily accessed through TV, with reservations about use of internet-enabled devices
While most caregivers believe in the opportunities other forms of EdTech might provide, their concerns around safety, inappropriate behaviour, and potential dependence on technology mostly hinder regular use of modalities such as smartphones, for example. TV is deemed a safer option. The need for supervision reduces the total number of hours of interaction by children on smartphones.

We do not want to have to have specific devices that are used for learning only as this will likely further reduce the uptake and continued use of EdTech. Therefore, in order to increase the use of EdTech through modalities such as smartphones, security concerns need to be addressed.

There are numerous ways in which this could occur, for example, through raising awareness and use of parental locks on smartphones to only allow access to approved content / websites; or working with EdTech hub producers to build into their platforms more advanced security restrictions and; teaching parents how to use these features.

\section{Female caregivers make most decisions around children's education in a household}

Our research shows that the most promising levers to improve access and use of EdTech are caregiver digital literacy, caregiver involvement, tech norms around education, and intention to educate children. It also reveals that the ideal audience for many potential interventions is the female caregiver. This is because it is the female caregiver (most often the mother) who makes most decisions around their children's education.

Therefore, interventions that aim to increase caregiver digital literacy, caregiver involvement in their children's education, and improve norms about the use of technology for education should focus on targeting female caregivers. This is due to their role as the primary decision-maker in a household when it comes to education. 
In theory, access to distribution channels should not differ between genders.

Unfortunately, everyday behaviour and engagement shows that it does
Our research has shown that while there are very few significant differences in the distribution of educational resources between girls and boys, and no significant differences between genders when it comes to the usefulness of common EdTech resources, there is a difference in engagement with educational resources between girls and boys.

As opportunities, behaviour, and engagement may differ between boys and girls, campaigns / interventions need to be designed with these considerations in mind.

For example, as girls are more likely to enjoy engaging in learning activities than boys, campaigns that target girls may want to highlight or be centred around this sense of enjoyment. 


\section{Conclusions}

Our qualitative and quantitative research looked at understanding the barriers, particularly for girls, to access and use of resources for learning and edutainment through smartphones and low-tech (radio, IVR, USSD, TV) EdTech solutions.

Our general findings from the study indicate that compatibility with the curriculum, price, quality and government license are the most important factors that caregivers consider when making decisions about educational resources for their children, regardless of gender. Most caregivers focus primarily on needing financial resources for textbooks, as this is perceived to be the resource that most closely aligns with the curriculum and is approved by the government. This is most likely rooted in the following.

1. A lack of awareness of how other materials link to the skills needed for national examinations.

2. A high level of trust in the Kenyan Government and its endorsement of educational materials.

As a trusted source of information, the Government of Kenya can play a significant role in driving learning at home. If it is possible for the government to directly make more content accessible through more diverse modalities (including EdTech products) or certify / approve third-party content, this could really help to improve learning at home. Further, caregivers' focus on the need for financial resources, textbooks, and compatibility with the curriculum stresses the importance of designing and communicating EdTech products in a way that addresses these concerns.

Two of the greatest gaps identified were a lack of guidance and a lack of conducive learning environments. With respect to guidance, trust and perceived professionalism (regarding the information provider) are particularly important in persuading caregivers to actually employ any advice they are given relating to EdTech. Critical information such as what educational materials exist, what is useful and for whom and how it should be used, either does not reach caregivers or feels too overwhelming to be understood. This is why so many caregivers ask for advice and feel relieved when they can get even the slightest advice from education professionals. Thus, avenues to increase this guidance would be very welcome. As far as learning environments are concerned, these are often full of distractions such as a lack of silence or lack of proper nutrition, or they tend to be scheduled for in the evening, when caregivers are around but children's attention span may be low. It may be possible to provide support with scheduling, whereby children and 
parents talk about plans for the day every morning or produce learning games that siblings can easily use together without the need for parental guidance in order to increase learning opportunities throughout the day.

Our findings specifically related to access and use of EdTech for girls show that caregivers report attempting to make learning resources available to their children in equal measure regardless of gender. However, they nonetheless treat children differently based on gender. This norm dissonance discovered by our research (caregivers stating directly and indirectly that they 'of course provide equal opportunities for all children but that others in their community prioritise boys') suggests the importance of shifting group norms before individual behaviour can truly change. To do this, we will need to include female caregivers as the target for interventions that foster wider change, as it is the female caregivers who seem to make most decisions around children's education, and who are likely to influence that change at home.

Further, this research has advanced our understanding of the non-structural barriers for girls in accessing and using EdTech in Kenya. However, there are some further areas to explore in future work. Based on correlational regressions, the following factors are the most promising levers for improving access and use of EdTech for girls.

- Improving digital literacy

- Increasing caregiver involvement

- Changing norms about technology for education

- Supporting intentions to provide equal educational opportunities for all children.

However, the correlational nature of this model means we need to be cautious about how we use the evidence, and we recommend further research to understand these relationships in greater depth, in order to establish causal links. Further, while increasing access to and use of EdTech has been, and is, crucial in supporting distance learning during and post the Covid-19 pandemic, it is also important to understand the impact that EdTech can have on norms and learning outcomes, with a focus on girls, in order to evaluate if investment in EdTech is an efficient, equitable, and cost-effective way to facilitate learning. 


\section{Bibliography}

Allier-Gagneur, Z., \& Moss Coflan, C. (2020). Your questions answered: Using technology to support gender equity, social inclusion and out-of-school learning. EdTech Hub. https://doi.org/10.53832/edtechhub.0025

Banerjee, A. V., Cole, S., Duflo, E., \& Linden, L. (2007). Remedying education: Evidence from two randomized experiments in India. Journal of Economics and Economic Education Research, 122(3), 1235-1264. https://doi.org/10.1162/qjec.122.3.1235

Bursztyn, L., Gonzalez, A. L., \& Yanagizawa-Drott, D. (2018). Misperceived social norms: Female labor force participation in Saudi Arabia.

https://home.uchicago.edu/bursztyn/Misperceived_Norms_2018_06_20. pdf

Common Market for Eastern and Southern Africa (COMESA). (2021, June 9). Kenya lauded for achieving 75\% electricity access rate.

https://www.comesa.int/kenya-lauded-for-achieving-75-electricity-acce ss-rate/

Cordeiro, V. C. (2020, December 15). Is 2020 a lost academic year? The impact of COVID-19 on education in eastern Africa: a case study of Kenya. Humanium.

https://www.humanium.org/en/is-2020-a-lost-academic-year-the-impa ct-of-covid-19-on-education-in-eastern-africa-a-case-study-of-kenya/

Crompton, H., Chigona, A., Jordan, K., \& Myers, C. (2021). Inequalities in girls' learning opportunities via EdTech: Addressing the challenge of Covid-19. EdTech Hub.

https://docs.edtechhub.org/lib/D6PWMC4l/download/LNDBFWHV/Cro mpton\%20et\%20al.\%20-\%202021\%20-\%2OInequalities\%20in\%20Girls_\%2 OLearning\%200pportunities\%20via\%20.pdf

Dam, R. F., \& Siang, T. Y. (n.d.). Define and Frame Your Design Challenge by Creating Your Point Of View and Ask "How Might We". The Interaction Design Foundation. Retrieved 12 October 2021, from https://www.interaction-design.org/literature/article/define-and-frameyour-design-challenge-by-creating-your-point-of-view-and-ask-how-m ight-we

Demirbas, O., \& Demirkan, H. (2007). Learning styles of design students and the relationship of academic performance and gender in design education. Learning and Instruction, 17(3), 345-359.

https://doi.org/10.1016/j.learninstruc.2007.02.007

Dias, P., Brito, R., Ribbens, W., Daniela, L., Rubene, Z., Dreier, M., Gemo, M., Di Gioia, R., \& Chaudron, S. (2016). The role of parents in the engagement of young children with digital technologies: Exploring 
tensions between rights of access and protection, from 'Gatekeepers' to 'Scaffolders'. Global Studies of Childhood, 6(4), 414-427. https://doi.org/10.1177/2043610616676024

Filmer, D. (2005). Gender and wealth disparities in schooling: Evidence from 44 countries. International Journal of Educational Research, 43(6), 351-369. https://doi.org/10.1016/j.ijer.2006.06.012

Giannini, S., \& Albrectsen, A.-B. (2020, March 31). Covid-19 school closures around the world will hit girls hardest. UNESCO.

https://en.unesco.org/news/covid-19-school-closures-around-world-willhit-girls-hardest

Global Education Monitoring Report Team. (2016). Education for people and planet: Creating sustainable futures for all [Global education monitoring report, 2016].

https://unesdoc.unesco.org/ark:/48223/pf0000245752

Global Partnership for Education. (2020). Application and program document for COVID-19 accelerated funding for Kenya.

https://www.globalpartnership.org/sites/default/files/document/file/202 0\%2008\%20COVID-19\%20AFF\%2ORequest\%2OKenya\%20-\%20Verified.p df

GSMA. (2020a). GSMA Connected Women: The mobile gender gap report 2020.

https://www.gsma.com/mobilefordevelopment/wp-content/uploads/20 20/05/GSMA-The-Mobile-Gender-Gap-Report-2020.pdf

GSMA. (2020b). Mobile internet connectivity 2020: Sub-Saharan Africa factsheet.

https://www.gsma.com/r/wp-content/uploads/2020/09/Mobile-InternetConnectivity-SSA-Fact-Sheet.pdf

GSMA. (2020c). Education for all in the time of COVID-19: How education can be part of the solution.

https://www.gsma.com/mobilefordevelopment/wp-content/uploads/20 20/09/EdTech-Final-WEB.pdf

Internet Society. (2017). Internet access and education: Key considerations for policy makers.

https://www.internetsociety.org/resources/doc/2017/internet-access-an d-education/

Kenya Health Information System (KHIS). (2020). Adolescents (age 10-19) presenting with pregnancy at health facilities. African Institute for Development Policy.

https://www.afidep.org/publication/adolescents-age-10-19-presentingwith-pregnancy-at-health-facilities/

Krumpal, I. (2013). Determinants of social desirability bias in sensitive surveys: A literature review. Quality \& Quantity, 47(4), 2025-2047. https://doi.org/10.1007/s11135-011-9640-9 
Kuroda, R., Lopez, M., Sasaki, J., \& Settecase, M. (2019). The digital gender gap. GSMA.

https://www.gsma.com/mobilefordevelopment/wp-content/uploads/20 19/O2/Digital-Equity-Policy-Brief-W20-Japan.pdf

Malala Fund. (2020). Girls' education and COVID-19: What past shocks can teach us about mitigating the impact of pandemics.

https://downloads.ctfassets.net/Ooan5gk9rgbh/6TMYLYAcUpjhQpXLDg mdla/3elc12d8d827985ef2b4e815a3a6dalf/COVID19_GirlsEducation_cor rected_071420.pdf

Naylor, R., \& Gorgen, K. (2020). Overview of emerging country-level response to providing educational continuity under COVID-19: What are the lessons learned from supporting education for marginalised girls that could be relevant for EdTech responses to COVID-19 in lowerand middle-income countries? (EdTech and Coronavirus (COVID-19)). EdTech Hub.

https://edtechhub.org/wp-content/uploads/2020/05/marginalised-girls. pdf

OECD. (2018). Bridging the digital gender divide: Include, upskill, innovate. https://www.oecd.org/digital/bridging-the-digital-gender-divide.pdf

Ölander, F., \& Thøgersen, J. (1995). Understanding of consumer behaviour as a prerequisite for environmental protection. Journal of Consumer Policy, 18(4), 345-385. https://doi.org/10.1007/BF01024160

Omidyar Network. (2019). Scaling access and impact: Realizing the power of EdTech [Executive summary].

https://ierc-publicfiles.s3.amazonaws.com/public/resources/Scaling_Ac cess_Impact_Realizing_Power_of_\%20EdTech.pdf

Plan International UK. (2019). Left out, left behind: Adolescent girls' secondary education in crises.

https://www.planinternational.nl/uploaded/2019/06/Left-out-Left-behin d-report.pdf?x65987

Presidential Policy and Strategy Unit (Kenya) \& Population Council. (2021). Promises to keep: Impact of COVID-19 on adolescents in Kenya. https://www.popcouncil.org/uploads/pdfs/2021PGY_ImpactCovidAdolKe nya.pdf

Rodriguez-Segura, D. (2020). Educational technology in developing countries: A systematic review [EdPolicyWorks Working Paper]. University of Virginia Curry School and Batten School. https://curry.virginia.edu/sites/default/files/uploads/epw/72_Edtech_in_ Developing_Countries.pdf

Rossing, J. P., Miller, W. M., Cecil, A. K., \& Stamper, S. E. (2012). ILearning: The future of higher education? Student perceptions on learning with mobile tablets. Journal of the Scholarship of Teaching and Learning, 12(2), 1-26. https://files.eric.ed.gov/fulltext/EJ978904.pdf 
Scaife, M., Rogers, Y., Aldrich, F., \& Davies, M. (1997). Designing for or designing with? Informant design for interactive learning environments. Proceedings of the ACM SICCHI Conference on Human Factors in Computing Systems, 343-350.

https://doi.org/10.1145/258549.258789

State Department of Early Learning and Basic Education. (2020). Kenya basic education COVID-19 emergency response plan. Republic of Kenya Ministry of Education.

https://www.education.go.ke/images/Kenya_basic_Education_COVID-19 _Emergency_Response_Plan-compressed.pdf

Szabo, G., \& Edwards, J. (2020). The Global Girlhood Report 2020: How COVID-19 is putting progress in peril. Save The Children.

https://resourcecentre.savethechildren.net/node/18201/pdf/global_girlho od_report_2020_africa_version_2.pdf

Tauson, M., \& Stannard, L. (2018). EdTech for learning in emergencies and displaced settings: A rigorous review and narrative synthesis. Save the Children.

https://resourcecentre.savethechildren.net/library/edtech-learning-eme rgencies-and-displaced-settings-rigorous-review-and-narrative-synthe sis

The Education Commission. (2016). The learning generation: Investing in education for a changing world.

https://report.educationcommission.org/wp-content/uploads/2016/09/L earning_Generation_Full_Report.pdf

The World Bank. (n.d.). Access to electricity (\% of population)—Kenya I

Data. Retrieved 3 October 2021, from

https://data.worldbank.org/indicator/EG.ELC.ACCS.ZS?locations=KE

The World Bank. (2021). Digital technologies in education.

https://www.worldbank.org/en/topic/edutech

UNESCO. (2020, April 29). 7.3 billion learners are still affected by school or university closures, as educational institutions start reopening around the world, says UNESCO.

https://en.unesco.org/news/13-billion-learners-are-still-affected-schooluniversity-closures-educational-institutions

UNICEF. (2016). Day of the Girl Child-2016.

https://weshare.unicef.org/CS.aspx?VP3=SearchResult\&ALID=2AMZIFM $2 O N Z$

UNICEF. (2020, June 4). Unequal access to remote schooling amid COVID-19 threatens to deepen global learning crisis.

https://www.unicef.org/press-releases/unequal-access-remote-schoolin g-amid-covid-19-threatens-deepen-global-learning

UNICEF Eastern and Southern Africa Region. (2016). Addressing social norms and gender in support of equity in education. 
https://www.unicef.org/esa/media/1741/file/UNICEF-ESA-2016-ProgramBrief-Education-Social-Norms.pdf

Vodafone Foundation. (2018). Real girls, real lives, connected: A global study of girls' access and usage of mobile, told through 3000 voices. https://static1.squarespace.com/static/5b8d51837c9327d89d936a30/t/5b be7bd6085229cf6860f582/1539210418583/GE_VO_Full_Report.pdf

Watson, C. (2014). Understanding changing social norms and practices around girls' education and marriage. ODI.

https://cdn.odi.org/media/documents/9572.pdf

Webb, D., Barringer, K., Torrance, R., \& Mitchell, J. (2020). Girls' education and EdTech: A rapid evidence review (Rapid Evidence Reviews).

EdTech Hub.

https://docs.edtechhub.org/lib/CZBRW85R/download/I4IK67WQ/Rapid \%20Evidence\%20Review\%20girls\%27\%20education\%20\%28published\% 29_FINAL.pdf

World Bank. (2020). How countries are using edtech (including online learning, radio, television, texting) to support access to remote learning during the COVID-19 pandemic.

https://www.worldbank.org/en/topic/edutech/brief/how-countries-are-u sing-edtech-to-support-remote-learning-during-the-covid-19-pandemi c

Zelezny-Green, R. (2011). The potential impact of mobile-assisted language learning on women and girls in Africa: A literature review. Ubiquitous Learning: An International Journal, 3(1), 69-82. https://doi.org/10.18848/1835-9795/cgp/v03i01/40257

Zelezny-Green, R. (2014). She called, she Googled, she knew: Girls' secondary education, interrupted school attendance, and educational use of mobile phones in Nairobi. Gender \& Development, 22(1), 63-74. https://doi.org/10.1080/13552074.2014.889338 


\section{Annex $1-$ Construction of outcome variables and indices}

\section{Unique variables}

For each of the chosen resources] Please estimate how many hours a day this child has time and opportunity to use the resource (without considering whether the child actually does use it this much).

[For each of the chosen resources] Which of these resources did this child actually use during school closures? Please estimate the hours per day for each chosen activity.

How many TVs are there in your household?

How many radios are there in your household?

How many smartphones are there in your household?

How many feature phones are there in your household?

Which of the following educational resources have you heard about?

If you did seek out educational material for your children, which channels did you use?

\section{The process}

Constructed

variable

The survey includes two main questions, which aim to measure the number of hours each child can access and actually uses certain resources. This ensures that if one measure provides noisy or confusing data, we are able to control/use the other one as a proxy.

For our final regressions, we only used a subset of the data that included values for girl children.

Hardware access $=$ TV + Radio + Smartphones + Feature phones

Create an ordinal variable which takes the value $=0$ if respondent has none of the hardware, value $=1$ if respondent has 1, 2 if the respondent has 2 , etc. to a maximum value of 4 .

Assign the value 1 to every educational resource respondents have heard about, and $\mathrm{O}$ otherwise.

Assign the value 1 to every channel for education material that the caregiver used.

Create a new variable by summing up the number

\section{Girls' access to EdTech - our} main outcome variable. Numeric variable (hours per day)

\section{Hardware access indicator}

Higher scores indicate better access to hardware.

\section{Information} access indicator Higher scores indicate better access to information about educational material. 


\begin{tabular}{|c|c|c|}
\hline & $\begin{array}{l}\text { of educational resources } \\
\text { and channels per } \\
\text { respondent. }\end{array}$ & \\
\hline $\begin{array}{l}\text { How comfortable are you using } \\
\text { a smartphone or tablet without } \\
\text { any help, on a scale of } 1 \text { to } 10 ?\end{array}$ & $\begin{array}{l}\text { Self-reported level of } \\
\text { comfort has a value } \\
\text { ranging from } 1-10\end{array}$ & $\begin{array}{l}\text { Digital literacy } \\
\text { indicator is a } \\
\text { numeric variable. } \\
\text { A higher score } \\
\text { indicates higher } \\
\text { levels of digital } \\
\text { literacy. }\end{array}$ \\
\hline $\begin{array}{l}\text { I believe (i) TV (ii) radio (iii) } \\
\text { feature phone (iv) smartphone } \\
\text { can be a useful and appropriate } \\
\text { medium for learning. }\end{array}$ & \multirow{6}{*}{$\begin{array}{l}\text { Assign values on the scale } \\
\text { as follows: } N / A=0, \text { strongly } \\
\text { disagree }=1, \text { mostly } \\
\text { disagree }=2 \text {, disagree }=3, \\
\text { agree }=4, \text { mostly agree }=5 \text {, } \\
\text { strongly agree }=6 \text {. } \\
\text { Compute the average } \\
\text { across the relevant } \\
\text { questions. }\end{array}$} & $\begin{array}{l}\text { General } \\
\text { attitudes } \\
\text { towards using } \\
\text { technology for } \\
\text { education }\end{array}$ \\
\hline $\begin{array}{l}\text { During school closures, girls in } \\
\text { my community spent less time } \\
\text { learning than boys. }\end{array}$ & & \multirow[t]{3}{*}{$\begin{array}{l}\text { Perceptions } \\
\text { indicator }\end{array}$} \\
\hline $\begin{array}{l}\text { It is important that every child } \\
\text { continues to learn during school } \\
\text { closures. }\end{array}$ & & \\
\hline $\begin{array}{l}\text { Female child(ren) in my } \\
\text { community tend to have access } \\
\text { to more learning resources than } \\
\text { male child(ren). }\end{array}$ & & \\
\hline $\begin{array}{l}\text { It was difficult to understand } \\
\text { which learning resources were } \\
\text { available for me and my } \\
\text { child(ren). }\end{array}$ & & \multirow[t]{2}{*}{$\begin{array}{l}\text { Perceived ability } \\
\text { indicator }\end{array}$} \\
\hline $\begin{array}{l}\text { I did not know which of the } \\
\text { existing resources would help } \\
\text { my child learn best. }\end{array}$ & & \\
\hline $\begin{array}{l}\text { Educational resources were } \\
\text { easily accessible during school } \\
\text { closures. }\end{array}$ & \multirow{2}{*}{$\begin{array}{l}\text { Assign values on the scale } \\
\text { as follows: } N / A=0, \text { strongly } \\
\text { disagree }=1, \text { mostly } \\
\text { disagree }=2 \text {, disagree }=3 \text {, } \\
\text { agre e }=4, \text { mostly agree }=5 \text {, } \\
\text { strongly agree }=6 \text {. } \\
\text { Compute the average } \\
\text { across the relevant } \\
\text { questions. }\end{array}$} & $\begin{array}{l}\text { Opportunity } \\
\text { indicator }\end{array}$ \\
\hline $\begin{array}{l}\text { I do my best to ensure all of my } \\
\text { children continue learning } \\
\text { during school closures }\end{array}$ & & $\begin{array}{l}\text { Intention } \\
\text { indicator }\end{array}$ \\
\hline
\end{tabular}




\begin{tabular}{|c|c|c|}
\hline $\begin{array}{l}\text { If a family has limited resources, } \\
\text { the boy should be prioritised in } \\
\text { providing access to learning } \\
\text { material / EdTech. }\end{array}$ & & $\begin{array}{l}\text { Gender norms } \\
\text { regarding } \\
\text { education }\end{array}$ \\
\hline $\begin{array}{l}\text { Girls should be able to learn the } \\
\text { same number of hours as boys. }\end{array}$ & & \\
\hline $\begin{array}{l}\text { Girls should have the same } \\
\text { access to educational material } \\
\text { as boys, no matter the medium } \\
\text { (TV, smartphone, radio, paper,...) }\end{array}$ & & \\
\hline $\begin{array}{l}\text { Girls should get access to } \\
\text { educational materials and } \\
\text { EdTech only if they are not } \\
\text { needed to help at home. }\end{array}$ & & \\
\hline $\begin{array}{l}\text { If there is only one smartphone / } \\
\text { tablet in the house, it is usually } \\
\text { used by... }\end{array}$ & \multirow{3}{*}{$\begin{array}{l}\text { For each male user / } \\
\text { decision-maker this } \\
\text { variable receives }+1 \text {, for each } \\
\text { female user/decision-maker } \\
\text {-1. It, therefore, measures } \\
\text { how 'male-dominated' } \\
\text { decisions around accessing } \\
\text { technology are. }\end{array}$} & \multirow[t]{3}{*}{$\begin{array}{l}\text { Household } \\
\text { demands / } \\
\text { decisions }\end{array}$} \\
\hline $\begin{array}{l}\text { Who decides most often about } \\
\text { who is allowed to use the } \\
\text { smartphone / tablet and when? }\end{array}$ & & \\
\hline $\begin{array}{l}\text { Would it be the same } \\
\text { decision-maker for TV and Radio } \\
\text { as for smartphone / tablet? }\end{array}$ & & \\
\hline $\begin{array}{l}\text { How many hours a day, on } \\
\text { average, do you spend doing } \\
\text { educational activities together } \\
\text { with this child? }\end{array}$ & \multirow{4}{*}{$\begin{array}{l}\text { Each of these scales will be } \\
\text { standardised } \\
\text { [standardised value }=X-\mu \\
/ \sigma] \\
\text { and summed up across all } \\
\text { four questions. }\end{array}$} & \multirow[t]{4}{*}{$\begin{array}{l}\text { Parent } \\
\text { involvement }\end{array}$} \\
\hline $\begin{array}{l}\text { How often do you encourage } \\
\text { this child to engage in } \\
\text { educational activities? }\end{array}$ & & \\
\hline $\begin{array}{l}\text { What are some of the things } \\
\text { you did to encourage this child } \\
\text { to learn? }\end{array}$ & & \\
\hline $\begin{array}{l}\text { In the months before Covid-19, } \\
\text { how often did you seek out } \\
\text { educational resources? }\end{array}$ & & \\
\hline
\end{tabular}




\section{Annex 2 - Fictional story}

The fictional story used in the qualitative interview guide:

"In a community in rural Kenya, school closures have affected households significantly, and due to Covid-19, it has become more difficult to earn enough income. Two families, in particular, are struggling and need to decide how to get by. They both value education very much and have 3 children aged 7-14. However, hard times require hard choices and so one family decides that only one child can continue to focus on learning (the boy, who is also the youngest) whereas the girls will help on the farm and in the family business. The other family has a friend who is a teacher and recommends that there are ways to keep learning, even if children also help out at home. The girls in the family start listening to educational radio programmes during household tasks, and the boys use the father's phone for USSD and IVR [IVR is when you call a number and a pre-recorded audio plays and you interact with it by pressing numbers on your phone] programmes while they are on the farm or selling products. In the evening, they share what they have learnt and watch an episode of an educational TV show together - this has really helped them to ensure all children keep learning while also managing their needs." 